\title{
On realistic size equivalence and shape of spheroidal Saharan mineral dust particles applied in solar and thermal radiative transfer calculations
}

\author{
S. Otto ${ }^{1}$, T. Trautmann ${ }^{2}$, and M. Wendisch ${ }^{1}$ \\ ${ }^{1}$ Leipzig Institute for Meteorology (LIM), University of Leipzig, Leipzig, Germany \\ ${ }^{2}$ Institut für Methodik der Fernerkundung (IMF), DLR Oberpfaffenhofen, Wessling, Germany \\ Received: 5 October 2010 - Published in Atmos. Chem. Phys. Discuss.: 30 November 2010 \\ Revised: 1 April 2011 - Accepted: 17 April 2011 - Published: 12 May 2011
}

\begin{abstract}
Realistic size equivalence and shape of Saharan mineral dust particles are derived from in-situ particle, lidar and sun photometer measurements during SAMUM-1 in Morocco (19 May 2006), dealing with measured sizeand altitude-resolved axis ratio distributions of assumed spheroidal model particles. The data were applied in optical property, radiative effect, forcing and heating effect simulations to quantify the realistic impact of particle nonsphericity. It turned out that volume-to-surface equivalent spheroids with prolate shape are most realistic: particle nonsphericity only slightly affects single scattering albedo and asymmetry parameter but may enhance extinction coefficient by up to $10 \%$. At the bottom of the atmosphere (BOA) the Saharan mineral dust always leads to a loss of solar radiation, while the sign of the forcing at the top of the atmosphere (TOA) depends on surface albedo: solar cooling/warming over a mean ocean/land surface. In the thermal spectral range the dust inhibits the emission of radiation to space and warms the BOA. The most realistic case of particle non-sphericity causes changes of total (solar plus thermal) forcing by $55 / 5 \%$ at the TOA over ocean/land and $15 \%$ at the BOA over both land and ocean and enhances total radiative heating within the dust plume by up to $20 \%$. Large dust particles significantly contribute to all the radiative effects reported. They strongly enhance the absorbing properties and forward scattering in the solar and increase predominantly, e.g., the total TOA forcing of the dust over land.
\end{abstract}

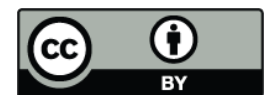

Correspondence to: S. Otto (sebasotto@gmx.de)

\section{Introduction}

Saharan mineral dust is one of the most abundant aerosols in the Earth's atmosphere and is transported from Africa to America over the Atlantic Ocean (Parkin et al., 1972; Doherty et al., 2008; Prospero et al., 2010). It is hence assumed to have a non-negligible influence on global climate. This impact may be the result of interactions between the radiation within the atmosphere and the dust particles leading directly to a certain heating. To study such processes with regard to atmospheric radiative effects (forcing) and atmospheric heating effects, the dust optical properties have to be determined to apply them in a radiative transfer model. However, these depend on a number of factors that make unique conclusions w.r.t. their radiative impact difficult. This is problematic, since ambiguities in the optical properties may occur when varying several parameters such as complex refractive index, typical dust size distributions, chemical composition, particle mixing state, size equivalence and particle shape. Thus, microscopic properties of the dust particles have to be considered as a starting point to simulate the optical properties and radiative transfer through dusty atmospheres (Sokolik et al., 2001). Measurements of the micro-physical properties of the dust particles are invaluable to realistically constrain some of the independent parameters. Such observations were extensively performed during the research project SAMUM-1 in May/June 2006. Its main aims were to investigate typical size distributions, the mineralogical as well as chemical composition and the realistic particle shape of the dust particles close to the source of their insertion into the atmosphere. This information can then be applied to simulate macro-physical ensemble optical properties such as the extinction as well as backscatter coefficient and the lidar ratio to be compared

Published by Copernicus Publications on behalf of the European Geosciences Union. 
with lidar observations as also performed during SAMUM1. Such comparisons may also help to constrain independent parameters, which is one of the goals of this paper, that is, to constrain realistic size equivalence and shape of Saharan mineral dust particles based on all available SAMUM-1 data that were important for this study.

Large dust particles have a big impact on the ensemble optical properties. As recently discussed, this particle fraction significantly increases the absorption of solar radiation, represented by a decreased single scattering albedo (SSA) in the visible spectral range (Otto et al., 2007; McConnell et al., 2008; Otto et al., 2009; McConnell et al., 2010), which affects the radiative budget. The realistic determination of large particles and the absorbing properties of the dust is, hence, very important, since uncertainties in the latter may have big effects when regionally modelling scenarios of dust outbreaks over Africa: Solmon et al. (2008) have shown that different cases of solar SSA result in different forcings and heating effects and, thus, cause different dynamical feedbacks, which influence regional precipitation in Northwest Africa. Mallet et al. (2009) simulated uncertainties in the solar and thermal dust forcing to which moderate changes in SSA may lead. It turned out that SSA affects surface forcing stronger than reasonable changes in the asymmetry parameter (ASP) and surface albedo. In combination with ASP these authors found that, keeping in mind that large particles enhance ASP and diminish SSA in the solar spectral range (Otto et al., 2007), a decrease/increase (and vice versa) in SSA/ASP results in radiative effects at the bottom of the atmosphere (BOA) counteracting each other. However, at the top of the atmosphere (TOA) the same changes in both SSA and ASP lead to radiative effects having the same sign. The combined radiative effect is comparable to that induced by changes in the surface albedo. Thus, large dust particles may have a big influence on the radiative and heating effects of atmospheric dust. The effect of SSA changes in simulated solar radiative fluxes at the surface has also been investigated recently by McFarlane et al. (2009), which was found to be larger than impacts due to reasonable changes in precipitable water vapour, ozone, surface albedo, total optical depth and ASP in the particular cases considered. In the thermal spectral range it is also the larger particles in the size distribution that impact the direct radiative effect (Hansell et al., 2010).

Due to the big influence of large particles exact size distribution measurements are essential. Efforts have been made to measure them (Weinzierl et al., 2009). Nevertheless each measurement is accompanied by certain inaccuracies (Reid et al., 2003) and, unfortunately, it is difficult to measure large particles, since they, e.g., may be picked by the inlet system (cut-off problem). Thus, we wish to study the effect of maximum particle size in a dust size distribution on optical properties and forcing in order to simulate the cut-off problem. In this context we would like to note that independent remote sensing techniques, e.g., to derive micro-physical particle properties from radiometric radiation measurements at the ground surface (Dubovik et al., 2002), may lead to SSA in the visible range, which is significantly larger than dust SSA calculated with in-situ data (Cattrall et al., 2003). Obviously, current retrievals of dust properties have certain inaccuracies as recently demonstrated by Müller et al. (2010).

Saharan mineral dust mainly consists of silicates with a volume fraction of $65-85 \%$ where the components of kaolinite and illite are most abundant. Second most frequent mineral group is carbonate followed by sulfates as reported by Coz et al. (2009) who investigated North African dust under different long-range transport scenarios. These results correspond to previous observations performed during SAMUM1 near the source region (Kandler et al., 2009; Otto et al., 2009). Moreover, Saharan mineral dust particles were found to be internally mixed as recently investigated by Dall'Osto et al. (2010) and Hand et al. (2010).

The assumption of homogeneous spherical dust particles is a further source of error in determining the dust forcing. Many studies have demonstrated the inadequacy of the homogeneous spherical approximation for non-spherical mineral dust particles (e.g. Schulz et al., 1998, 1999; Kahnert, 2004; Veihelmann et al., 2006; Kahnert and Nousiainen, 2006; Kahnert et al., 2007). That it may even be one of the dominant sources of error in quantifying the forcing of mineral dust has been shown by Kahnert and Kylling (2006), Kahnert et al. (2005) and Otto et al. (2009) who assumed spheroidal model particles to account for particle non-sphericity. A spheroidal particle can either be of prolate or oblate shape and is described by the axis ratio (AR) of its half axes. Coz et al. (2009) measured cross sections of non-spherical dust particles, which were fitted to ellipses of certain ARs. They determined particle size, characterised by a size-equivalent diameter $D_{\mathrm{e}}$, by assuming cross section equivalence and prolate particle shape. It turned out that the most frequent $\mathrm{AR}$ is about 1.8 and is reported to be larger than ARs observed close to source regions. This corresponds to Kandler et al. (2009) who measured AR distributions during SAMUM-1 with maxima at about 1.5 for dust particles collected closer to source region. However, the treatment of prolate shape and cross section equivalence is only one possibility to approximate non-sphericity. In contrast Otto et al. (2009) found oblate shape and volume equivalence to be most representative for dust particles as observed during SAMUM-1. But these authors assumed a "constant AR" for each model particle, a term which meant and also means henceforth that AR does not vary with particle size and no (frequency) distribution of AR is applied for every model particle. However, in the present paper we deal with such AR distributions, measured during SAMUM-1 and varying with particle size, to derive the realistic particle shape and size equivalence.

The vertical distribution of a dust layer (Quijano et al., 2000; Gómez-Amo et al., 2010) and the spectral albedo (Bierwirth et al., 2009) of the underlying ground surface is also important when quantifying the radiative forcing of the 
Saharan mineral dust. Therefore we wish to apply vertical profile data of the dust and surface albedo data, measured during SAMUM-1, in our simulations in which a dust plume is assumed to be located over a mean land and ocean surface.

In the context of the previous discussion and latest literature we would like to mention that the assumptions w.r.t. size distribution, chemical composition, mixing state and particle model as made by Otto et al. (2009) can be treated to be realistic with regard to Saharan mineral dust. Thus, that work is the basis for our present study.

Section 2 summarises the SAMUM-1 measurements on which our study is based. Section 3 describes the radiative transfer calculations performed within the scope of our sensitivity studies w.r.t. optical properties (Sect. 4), radiative effects (Sect. 5) and dust forcing (Sect. 6) with regard to the impact of particle non-sphericity. The latter is also discussed in heating effect simulations in Sect. 7. Finally, Sect. 8 offers conclusions.

\section{Observations and in-situ data during SAMUM-1}

The first measurement campaign of the SAMUM consortium took place in May and June 2006 in Morocco (SAMUM-1), around Zagora (ZGA, $\sim 730 \mathrm{~m}$ above sea level [a.s.1.]), Tinfou ( $720 \mathrm{~m}$ a.s.1.) and Ouarzazate (OZT, $\sim 1150 \mathrm{~m}$ a.s.1.). An overview of SAMUM-1 can be found in Heintzenberg (2009). In the following we refer to the campaign day 19 May 2006 and to the measured data, which were important for our paper. These are given next: (1) environmental conditions (Tesche et al., 2009), that is, vertical profiles of pressure, temperature and relative humidity, (2) size distributions of the airborne Saharan dust (Weinzierl et al., 2009), (3) chemical composition as a function of particle size (Kandler et al., 2009) and (4) spectral surface albedo in the solar spectral range (Bierwirth et al., 2009). Based on these comprehensive observations it was possible to start with microscopic properties of the dust particles as claimed by Sokolik et al. (2001), e.g., a size-resolved complex refractive index of the observed dust ensemble was derived (Otto et al., 2009), which is also applied in our recent radiation simulations.

The treatment of non-spherical dust particles leads to additional free variables, that is, size equivalence and particle shape, which have to be constrained by observations. Kandler et al. (2009) performed single particle analyses of ground- and aircraft-based in-situ data and fitted ellipses to the cross sections of the observed dust particles to derive particle axis ratio (AR) distributions as a function of a volumeequivalent diameter $D_{\mathrm{p}}$ (Fig. 1), that is, the assumption of spheroidal model particles is reasonable. Nevertheless, the actual shape (prolate or oblate) is uncertain due to the experimental limitations and we may realistically assign the measured functional relation between $\mathrm{AR}$ and $D_{\mathrm{p}}$ to $\mathrm{AR}$ as a function of the equivalent diameter $D_{\mathrm{e}}$ defined in Sect. 3.2 when dealing with both prolate and oblate model particles.

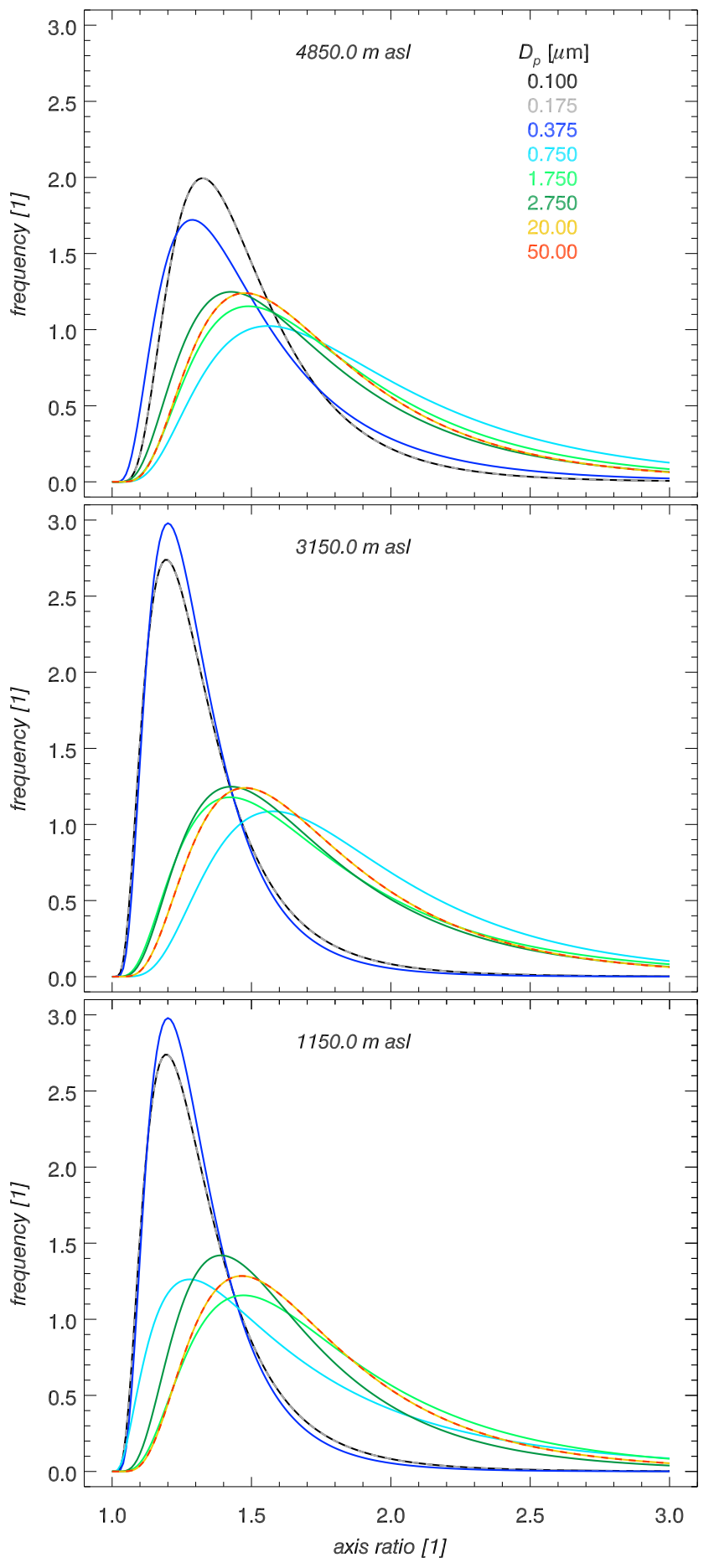

Fig. 1. Frequency of dust particle axis ratio (AR) as a function of particle size $D_{\mathrm{p}}$ and altitude, derived by Kandler et al. (2009) on 19 May 2006 during SAMUM-1 over Morocco. The cross sections of the individual particles were measured and fitted to ellipses of certain ARs. Although the observations did not provide information about the real particle shape, a prolate spheroid was assumed w.r.t. each particle by rotating the ellipse around the longest half axis to derive $D_{\mathrm{p}}$ as the volume-equivalent diameter of this spheroid. 
For constraining particle non-sphericity, that means size equivalence and particle shape, the ground-based (Tesche et al., 2009) and aircraft-based (Esselborn et al., 2009) lidar measurements that were performed during SAMUM-1 will be applied, which were already used in the previous paper of Otto et al. (2009). These authors simulated vertical profiles of the dust backscatter coefficient and lidar ratio, assuming spheroidal particles, and compared them with the lidar data. They found oblate particles and volume equivalence to be most probable. However, in that study constant ARs were assumed for each model particle, which is less realistic. Hence, we wish to apply the AR distributions as have been measured during SAMUM-1.

\section{Radiative transfer calculations}

\subsection{The applied model}

The latest version of the radiative transfer model TRAVIS (Toolbox for Radiative transfer Applications from ultraViolet to far-Infrared wavelengthS) is applied. Its basic features are described in previous papers (Otto et al., 2007, 2009). The following issues were revised or extended:

- Running modes with variable spectral resolution: lineby-line, fine- or broad-band.

- Incident solar constant correction according to the day of year (Zdunkowski et al., 2007).

- Ground elevation.

- Rayleigh scattering parameterisations (Bates, 1984; Nicolet, 1984; Bucholtz, 1995; Thomas and Stamnes, 1999; Bodhaine et al., 1999).

- Aerosol and cloud parameterisations (Shettle and Fenn, 1979; Stephens, 1979; Slingo, 1989; Hu and Stamnes, 1993; Dobbie et al., 1999; Lindner and Li, 2000).

- Latest HITRAN data (Rothman et al., 2009) to calculate gas absorption.

- Spectral surface albedo data (Bowker et al., 1985; Feister and Grewe, 1995; Baldridge et al., 2009).

- Scattering database for single (homogeneous and orientation-averaged) spheroidal particles extended by exact null-field (NF) method in the transition region of this method and geometrical optics approximation (GOA) methods (for details to the codes applied see Otto et al., 2009, and the corresponding works cited therein), that is, for volume-equivalent size parameters between 50 and 100; Interface to a second scattering database (Schmidt et al., 2009) based on an independent $\mathrm{NF}$ code.
While TRAVIS was applied in simulations of the radiative transfer through a Saharan mineral dust plume in a limited solar spectral range ( 0.318 to $2.167 \mu \mathrm{m})$ within the scope of a radiative closure study (Otto et al., 2009), according to the radiation and surface albedo measurements during SAMUM1 (Bierwirth et al., 2009), we now consider the total solar range $(0.2$ to $4 \mu \mathrm{m})$ and, additionally, the thermal spectral region (4 to $40 \mu \mathrm{m}$ ).

\subsection{The treatment of spheroidal dust particles}

Natural dust particles are non-sphercial. The "diameter" $D_{\mathrm{p}}$ of a measured particle is, thus, always an equivalent diameter $D_{\mathrm{e}}$, a notation that is prefered in the following. As discussed in Sect. 2 dust particles may be approximated by model spheroids. Since SAMUM-1 did not provide information about size equivalence, we may interpret the measured quantity $D_{\text {e }}$ w.r.t. a model spheroid as follows:

1. Volume equivalence (VEQV): $D_{\mathrm{e}}$ is the diameter of a sphere having the same volume as the spheroid.

2. Surface equivalence (SEQV): $D_{\mathrm{e}}$ is the diameter of a sphere having the same surface area as the spheroid.

3. Volume-to-surface equivalence (VSEQV): $D_{\mathrm{e}}$ is the diameter of a sphere having the same volume-to-surface area ratio as the spheroid.

4. Longest axis equivalence (LAEQV): $R_{\mathrm{e}}=\frac{1}{2} D_{\mathrm{e}}$ is the length of the longest half-axis of the spheroid (maximum dimension).

5. Shortest axis equivalence (SAEQV): $R_{\mathrm{e}}=\frac{1}{2} D_{\mathrm{e}}$ is the length of the shortest half-axis of the spheroid (minimum dimension).

In each case of size equivalence and a measured particle of diameter $D_{\mathrm{e}}$ we may calculate the diameter $D_{\mathrm{v}}$ of a second sphere having the same volume as the respective model spheroid. Then $D_{\mathrm{v}}$ is a function of $D_{\mathrm{e}}$ and the aspect ratio (ASR) $\epsilon$, which may be defined to be $<1$ for prolate and $>1$ for oblate spheroids (Otto et al., 2009). Based on $D_{\mathrm{v}}$ the volume-equivalent size parameter is defined by $x_{\mathrm{v}}=\frac{\pi D_{\mathrm{v}}}{\lambda}$ that also depends on $D_{\mathrm{e}}$ and $\epsilon$. Figure 2 shows $x_{\mathrm{v}}$ as a function of $D_{\mathrm{e}}$ at three wavelengths for a prolate $\left(\epsilon=\frac{1}{2}\right)$ and an oblate $(\epsilon=2)$ spheroid (both having the same AR of $2: 1$ ) in all cases of size equivalence. Large particles $\left(D_{\mathrm{e}}>\sim 3 \mu \mathrm{m}\right)$ may lead to values of $x_{\mathrm{v}}$ much larger than 50 (drawn as black horizontal line in Fig. 2), which is an approximate bound up to which recent exact scattering codes converge. In the spectral transition region to and within the thermal range $(\lambda \geq 4 \mu \mathrm{m}) x_{\mathrm{v}}$ do mostly not exceed 50 , that is, the extinction properties of a single model spheroid are provided by exact NF methods. Size equivalence has a big influence on the size (parameter) of a single model spheroid. 
The determination of $x_{\mathrm{v}}$ of a single model spheroid is required, since its extinction properties are stored in recent databases (Otto et al., 2009; Schmidt et al., 2009) as a function of $x_{\mathrm{v}}$ and $\epsilon$ as well as of the real $n_{\mathrm{R}}$ and imaginary part $n_{\mathrm{I}}$ of a complex refractive index. To yield the optical properties of an observed dust ensemble, the measured size distribution $N\left(D_{\mathrm{e}}\right)$ must be integrated w.r.t. $D_{\mathrm{e}}$ weighted by the single particle extinction properties. Thus, for $D_{\mathrm{e}}$ within the size bin $d D_{\mathrm{e}}, x_{\mathrm{v}}$ has to be computed before database access. Since $x_{\mathrm{v}}$ depends on $D_{\mathrm{v}}$ and $\lambda$ as well as $D_{\mathrm{v}}$ on $D_{\mathrm{e}}, \epsilon$ and size equivalence, the latter two variables can be freely selected next to $\lambda$. For example, Otto et al. (2009) considered constant ARs for prolate and oblate model spheroids, while we wish to average over our measured AR distributions (Fig. 1). Such an integration is performed w.r.t. $\epsilon^{\prime} \geq 1\left(\epsilon^{\prime}=1\right.$ for spheres $)$ that $\epsilon=\frac{1}{\epsilon^{\prime}}$ for prolate and $\epsilon=\epsilon^{\prime}$ for oblate spheroids. Finally, only size equivalence and particle shape (prolate or oblate) are the independent parameters when simulating the spectral optical properties of the dust.

A more detailed description of the treatment of spheroidal dust particles and the accuracy of the combination of NF and GOA methods to compute single spheroid optical properties are given by Otto (2011).

\subsection{The cut-off problem}

Due to technical limitations the sampling of large particles $\left(D_{\mathrm{e}}>\sim 3 \mu \mathrm{m}\right)$ is problematic. Recent studies report that losses of coarse mode particles may occur (Reid et al., 2003; Linke et al., 2006; Johnson et al., 2008a; McConnell et al., 2008; Chen et al., 2011). While Schmid et al. (2000) performed cut-off corrections, McConnell et al. (2010) refer the optical properties, based on size-limited particle information, to the observed accumulation mode of the entire dust ensemble. The same should be done, e.g., for imaginary parts of the complex refractive index or single scattering albedo in the visible spectral range derived from limited particle data (Haywood et al., 2003; Osborne et al., 2008; Johnson et al., 2008b; Raut and Chazette, 2008; Johnson et al., 2009; McFarlane et al., 2009), which then may not be representative for the entire dust population. For demonstration how these particle losses affect the dust optical properties and radiative effects we perform integrations of size distributions stepwise up to various maximum particle diameters $D_{\mathrm{e}, \max }$ (Sects. 4.1 and 6.1).

\subsection{Atmospheric radiative effect - forcing}

The net radiative flux density is defined by $F_{n}(z, \lambda)=$ $F_{+}(z, \lambda)-F_{-}(z, \lambda)$ where $F_{+}$and $F_{-}$mean the upward and downward spectral irradiances at a certain altitude $z$ and wavelength $\lambda$. The so-called atmospheric radiative effect or forcing, a notation that we prefer for simplification, at $z$ is generally given by spectrally integrating the deviations in simulated net flux densities compared to a reference scenario,

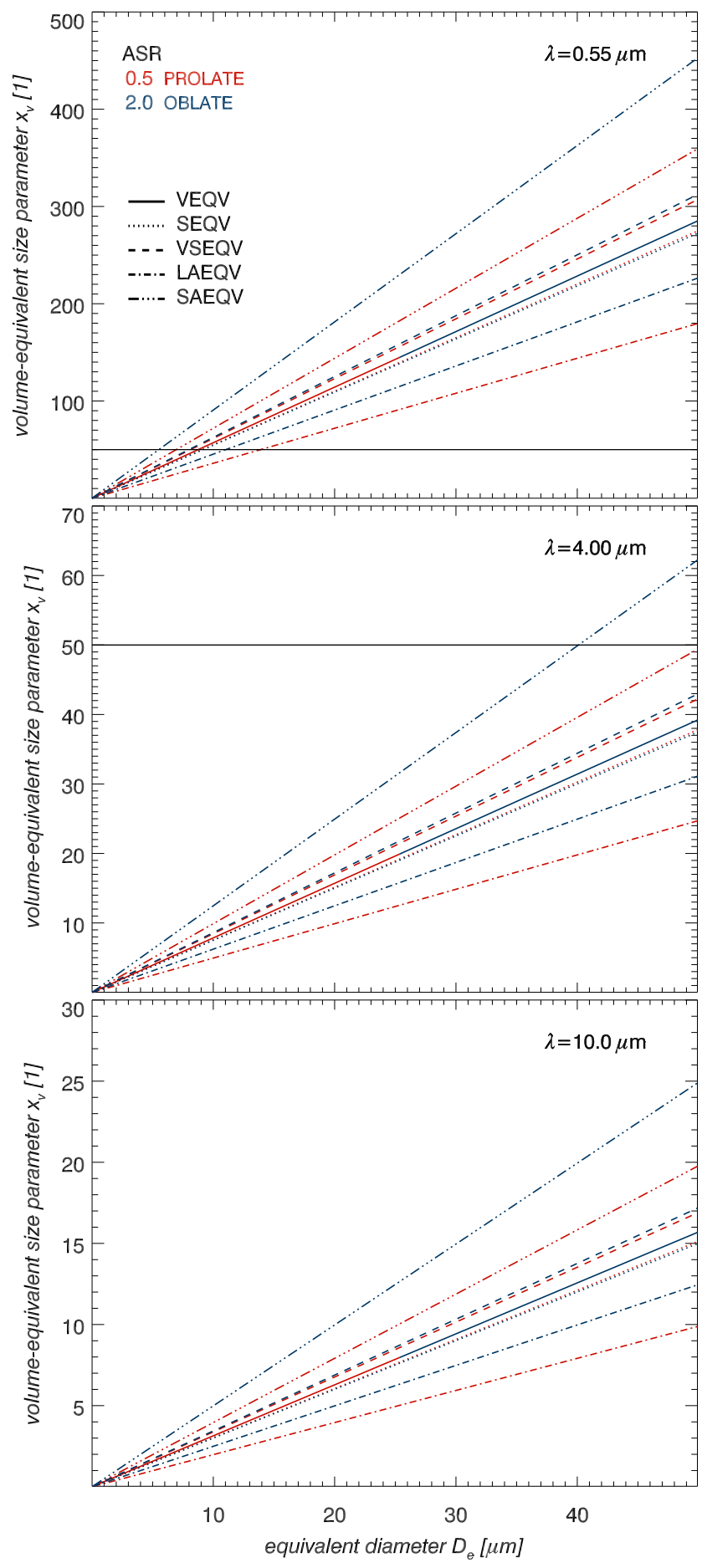

Fig. 2. Volume-equivalent size parameter $x_{\mathrm{v}}$ as a function of the equivalent diameter $D_{\mathrm{e}}$ of a measured particle, which is represented by a prolate and an oblate model spheroid with an AR of $2: 1$ in cases of five types of size equivalence. (top) At $550 \mathrm{~nm}$, (centre) at $4 \mu \mathrm{m}$ and (bottom) at $10 \mu \mathrm{m}$ wavelength. The horizontal black lines in the top and centre figures correspond to a size parameter of 50, an approximate value above which current exact scattering codes do not converge. 


$$
\Delta F(z)=\int_{I_{\Delta \lambda}}\left[F_{n}(z, \lambda)-F_{n}^{r}(z, \lambda)\right] d \lambda
$$

in units of $\mathrm{W} \mathrm{m}^{-2}$ where $F_{n}$ denotes the perturbed and $F_{n}^{r}$ the reference case (Otto et al., 2009). $I_{\Delta \lambda}$ is certain spectral interval covering wavelengths from 0.2 to $4 \mu \mathrm{m}$ in the solar and from 4 to $40 \mu \mathrm{m}$ in the thermal spectral range.

If the amount of the incoming solar radiation is equal for both cases, as we assume in the following, Eq. (1) results in

$$
\Delta F(\mathrm{TOA})=\int_{I_{\Delta \lambda}}\left[F_{+}(\mathrm{TOA}, \lambda)-F_{+}^{r}(\mathrm{TOA}, \lambda)\right] d \lambda
$$

at the top of the atmosphere (TOA). This forcing describes the radiation loss of the local Earth-atmosphere system (EAS). For the bottom of the atmosphere (BOA) we refer to Otto et al. (2009) and consider changes in the downward radiation as it would be observed by a radiation measurement instrument, that is, we define the forcing independently of Eqs. (1) and (2) by

$$
\Delta F(\mathrm{BOA})=\int_{I_{\Delta \lambda}}\left[F_{-}(\mathrm{BOA}, \lambda)-F_{-}^{r}(\mathrm{BOA}, \lambda)\right] d \lambda .
$$

Forcings were computed in the solar and thermal spectral range. The sum of both yields the total forcing. A reference scenario always represents a clear-sky atmosphere, which consists of absorbing and Rayleigh scattering gas molecules only. Each perturbed atmosphere additionally contains the observed Saharan mineral dust where particles are treated as spheres and spheroids. The surface albedo is also equal for a forcing simulation but differs in cases of the dust over land and ocean as underlying surface.

To show, e.g., the effects of the particle non-sphericity the so-called change of forcing is simulated in units of $\%$ by comparing the forcing of spheroidal and spherical particles (Sect. 6).

\subsection{Atmospheric heating effect}

Based on net radiative flux density, specific heat $c_{\mathrm{p}}$ and air density $\rho$, the vertical radiative heating rate is defined by

$H(z)=-\frac{1}{c_{\mathrm{p}} \rho(z)} \int_{I_{\Delta \lambda}} \frac{d F_{n}(z, \lambda)}{d z} d \lambda$,

which may be computed for a local model atmosphere in the solar, thermal and total spectral range $I_{\Delta \lambda}$. Simulating the radiative heating rates of a perturbed scenario $H(z)$ and of a reference case $H^{r}(z)$, analogously to the forcing concept (Sect. 3.4), the so-called heating effect is given by

$\Delta H(z)=H(z)-H^{r}(z)$ where the reference scenario refers to clear-sky conditions and surface albedo is the same in both cases as well.

To compare the heating effects of two different sets of certain free parameters, e.g., spherical or spheroidal model particles, a so-called change of heating effect is computed in units of \% (Sect. 7).

\subsection{The assumed scenarios}

The computations are based on two main scenarios of the in-situ observed dust within a realistic model atmosphere (molecular absorption and Rayleigh scattering) above a land and an ocean surface. For both ground types an averaged spectral Lambertian albedo is applied, depicted as dashed orange curves in Fig. 3: in the case of the land surface ASTER data and SAMUM-1 measurements on 19 May 2006 were combined to extend the latter to the ultraviolet and thermal spectral region (top). For the ocean case a mean spectral albedo was computed with the help of a moving average over wavelength based on several datasets covering different spectral ranges (bottom).

TRAVIS was prepared as given next:

- While in the case of land the environmental conditions observed around OZT site on 19 May 2006 (see Sect. 2) are applied, namely a model atmosphere down to $1.15 \mathrm{~km}$ a.s.1. (OZT), we assume a tropical standard atmosphere (Anderson et al., 1986) down to $0 \mathrm{~km}$ a.s.l. in the ocean case. In both situations the dust layer ranges from 1.15 to $5.6 \mathrm{~km}$ a.s.l. such that the ocean scenario represents the case of the same dust plume but lifted as during long-range transport over the Atlantic ocean.

- Dust load and layering as reported by Otto et al. (2009) based on in-situ size distribution measurements (Weinzierl et al., 2009) and vertical profiling (Esselborn et al., 2009; Tesche et al., 2009).

- Size-resolved complex refractive index of the dust as derived by Otto et al. (2009) based on in-situ measured chemical composition data (Kandler et al., 2009).

- Vertical resolution of $\Delta z=25 \mathrm{~m}$ over land and $100 \mathrm{~m}$ over ocean surface from ground up to an altitude of $20 \mathrm{~km}$ a.s.l. Above $20 \mathrm{~km}$ in both cases a vertical increment of $\Delta z=1 \mathrm{~km}$ is assumed up to a maximum altitude of $70 \mathrm{~km}$ a.s.l. This means 489 and 250 homogeneous layers over land and ocean.

- Fine-band mode with a spectral wavelength resolution: $\Delta \lambda=1 \mathrm{~nm}$ between 0.2 and $2.170 \mu \mathrm{m}, \Delta \lambda=2.5 \mathrm{~nm}$ between 2.170 and $5 \mu \mathrm{m}$, and a wavelength increment $\Delta \lambda$ according to a wavenumber resolution of $1 \mathrm{~cm}^{-1}$ between 5 and $40 \mu \mathrm{m}$ wavelength.

- Ozone column of 290.5 DU in all cases representing 19 May 2006 during SAMUM-1 (Bierwirth et al., 2009). 
- Solar constant of $1365.5 \mathrm{Wm}^{-2}$ for 2006 (Shanmugam and Ahn, 2007) corrected to day 139 of year (19 May).

- Solar zenith angle of $0^{\circ}$ in all computations; averaged spectral surface albedos of Fig. 3 (dashed orange curves); surface temperature for land of $50{ }^{\circ} \mathrm{C}$ (Bierwirth et al., 2009) and for ocean of $22^{\circ} \mathrm{C}$ (Otto et al., 2007); surface emissivity of 1.0 that is comparable to the mean value of 0.97 observed during SAMUM-1 at OZT by Ansmann et al. (2009).

- Discrete ordinate solver is used with 32 streams and the same number Legendre expansion coefficients of the scattering phase function.

Main differences to the previous investigations (Otto et al., 2009) are the following: we now consider the total (solar plus thermal) spectral range and in-situ measured AR distributions (Fig. 1) that vary with particle size and altitude instead of constant axis ratios for each model particle when dealing with spheroidal scatterers. With both particle models we wish to demonstrate the ambiguities to which the treatment of non-spherical particles may lead (Sect. 4.2).

The dust particles involved are treated as spheres and spheroids (Sect. 3.2). Full-spectral ensemble integrated optical properties and irradiance fields with and without the measured dust are presented (Sects. 4 and 5).

In all cases of the Saharan mineral dust (over land and ocean) forcings and heating effects are simulated for both spherical and under various assumptions of spheroidal model particles. Then changes of forcing and heating effect are computed by varying the particle model (Sects. 6 and 7). The simulations are performed separately for solar, thermal and total spectral range.

\section{Optical properties}

\subsection{Large spherical particles and imaginary part}

Otto et al. (2007) computed the spectral single scattering albedo $\varpi$ of a dust plume over the Canary Islands based on literature data of the spectral complex refractive index of dust. Large particles $\left(D_{\mathrm{e}}>\sim 3 \mu \mathrm{m}\right)$, which were observed at lower altitudes, led to smaller values of $\varpi$ at visible wavelengths (Solmon et al., 2008) compared to higher altitudes where no large particles were found. To point out the role of these particles these authors calculated band-averaged single scattering albedo, size integrated up to a maximum particle diameter $D_{\mathrm{e}, \max }$. Here we avoid spectral averaging and present the full-spectral $\varpi$ of the dust over Morocco, based on refractive index data derived from measurements, in cases of various values of $D_{\mathrm{e}, \max }$ as depicted in Fig. 4. The same was done for the asymmetry parameter, which is shown in Fig. 5. Both images illustrate the impact of the large particles: these result in enhanced absorption/scattering in the
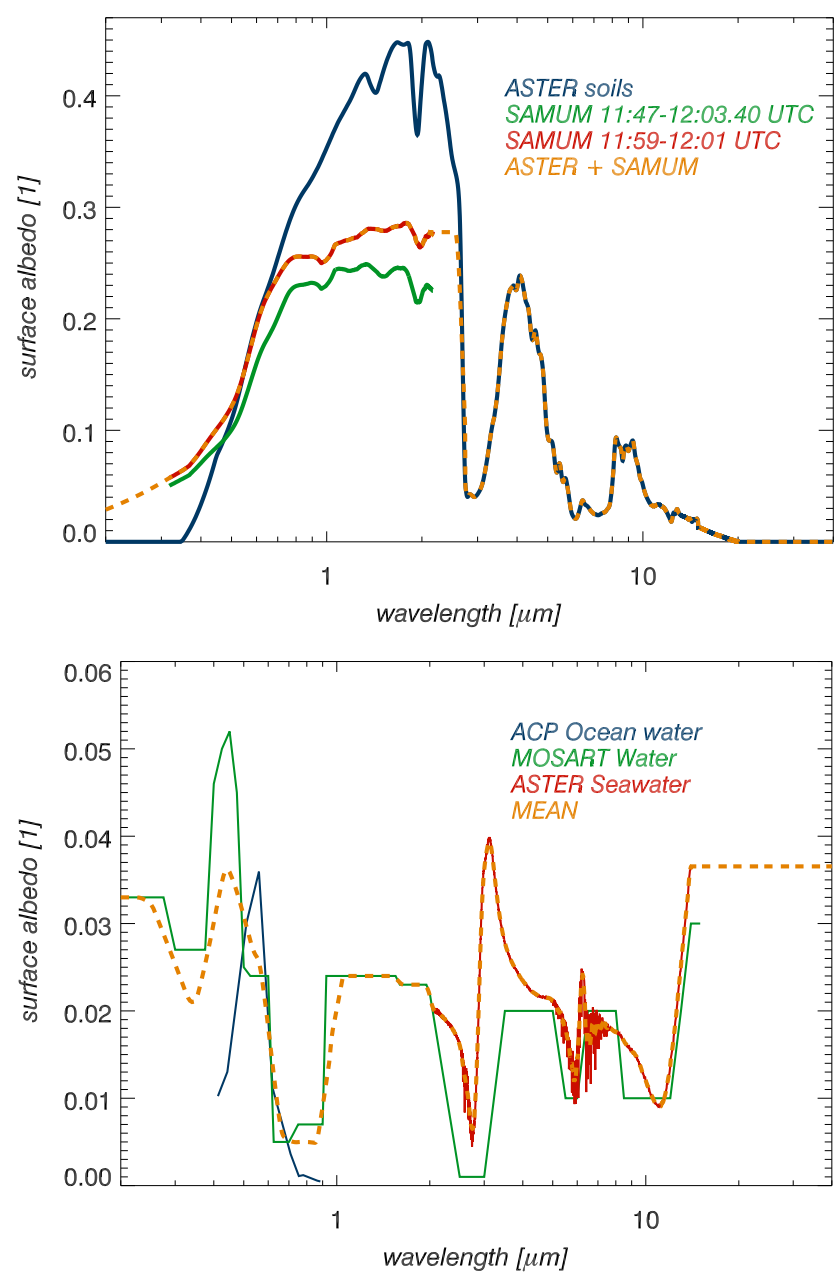

Fig. 3. Averaged spectral surface albedo (dashed orange curves) as used in our solar and thermal radiative transfer simulations. (top) Land surface: 101 datasets, measured on 19 May 2006 during SAMUM-1 (Bierwirth et al., 2009), were averaged over time (green and red curves correspond to different time intervals around noon) and are combined with an averaged soil albedo based on 58 datasets of ASTER (Baldridge et al., 2009). (bottom) Ocean surface: data (blue) received by Schröder (2004) as used in Otto et al. (2007), provided by MOSART (Cornette et al., 1994, green) for water and ASTER for seawater (red) were spectrally averaged.

solar/thermal and cause increased forward scattering over the entire spectral range. With regard to the cut-off problem (Sect. 3.3) we emphasise that a neglect of this particle fraction, caused by technical limitations in particle measurements, leads to optical properties which are not representative for the entire dust population.

The dust optical properties also depend on the spectral complex refractive index assumed. The single scattering albedo that is displayed in Fig. 4 is based on a size-resolved refractive index with values of 1.51-1.55 (real part) and $0.0008-0.006$ (imaginary part) at $550 \mathrm{~nm}$ (Otto et al., 2009). 


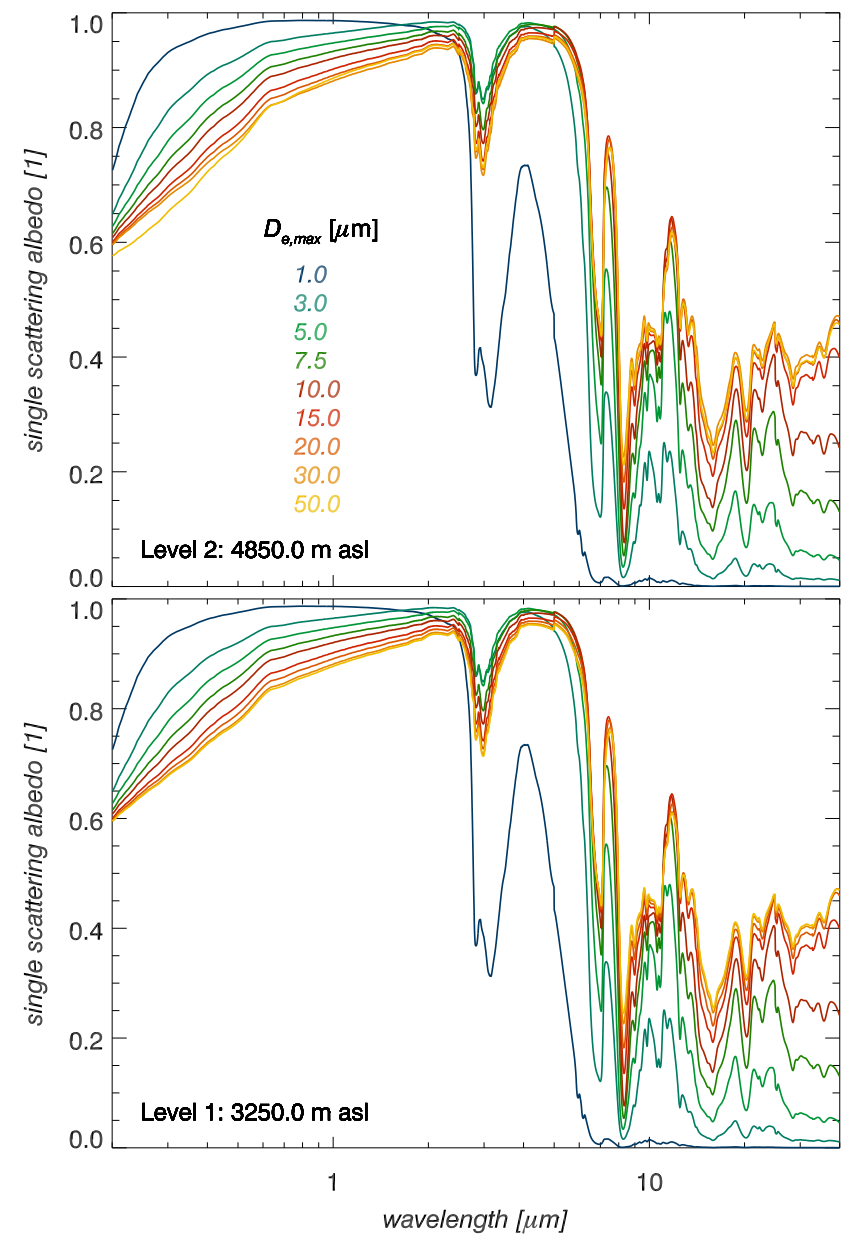

Fig. 4. Single scattering albedo of spherical Saharan mineral dust particles at the two altitude levels of the number concentration size distribution measurements, on 19 May 2006 over OZT site about noon (Weinzierl et al., 2009), as a function of wavelength. Modal parameters, which were fitted to the data, were applied for size integration up to a maximum particle diameter $D_{\mathrm{e}, \max }$. The coloured curves represent various values of $D_{\mathrm{e}}$, max between 1 and $50 \mu \mathrm{m}$.

To account for uncertainties in the imaginary part (IM) we performed a second sensitivity study at $532 \mathrm{~nm}$ (lidar wavelength) by treating all particles to have the same value of IM. Varying IM in the reasonable range between 0.0008 and 0.008 and $D_{\mathrm{e}, \max }$ we found that a decrease of IM counteracts an increase of $D_{\mathrm{e}, \max }$ (Fig. 6). In other words, two different combinations of IM and $D_{\mathrm{e}, \max }$ may lead to the same value of $\varpi$. This ambiguity might be one reason for difficulties in simultaneous derivation of imaginary part and coarse mode fraction by recent dust retrievals (Müller et al., 2010).

Figure 6 shows that $\varpi$ depends strongly on $D_{\mathrm{e}, \max }$ for values $D_{\mathrm{e}, \max } \leq \sim 20 \mu \mathrm{m}$. For larger values $\varpi$ does not change significantly. This might lead to the conclusion that large particles $D_{\mathrm{e}, \max }>\sim 20 \mu \mathrm{m}$ might be negligible. However, these particles contribute significantly to the total dust op-

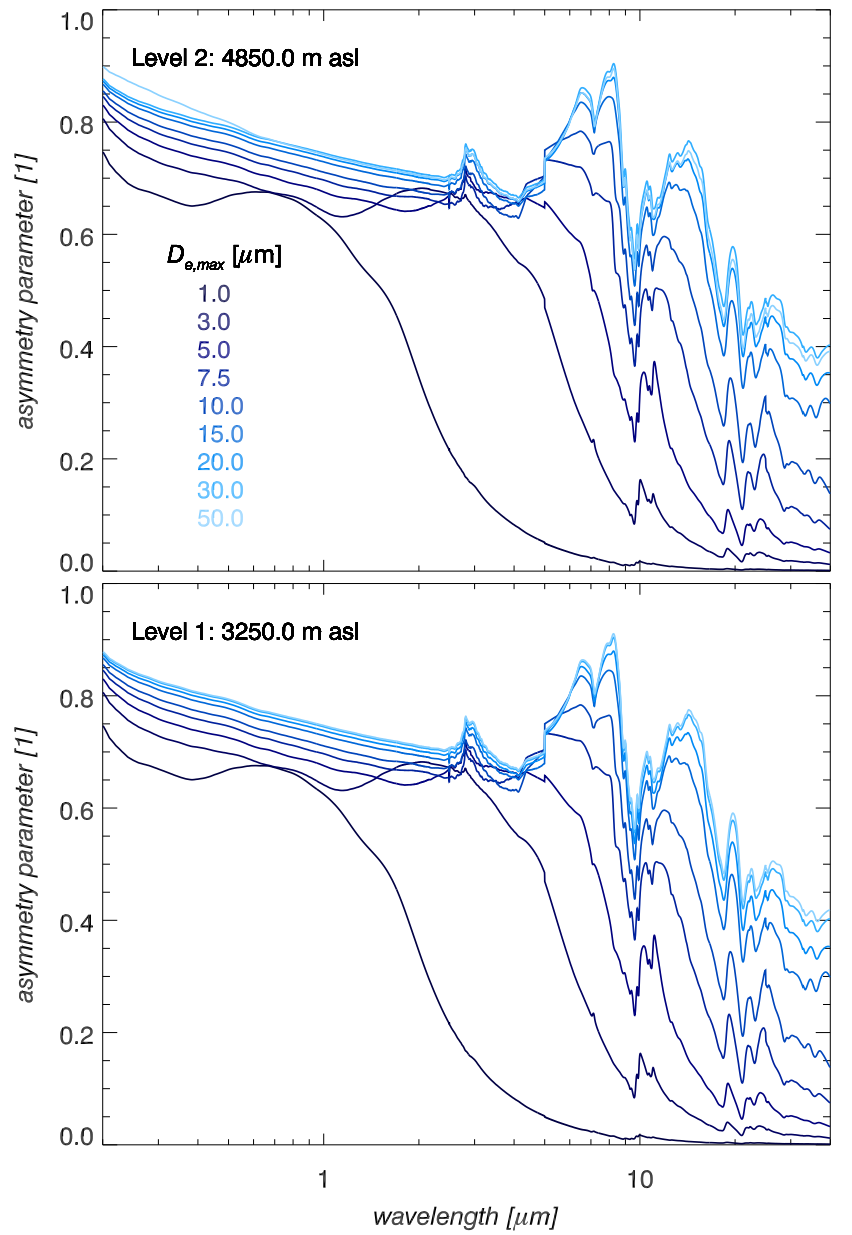

Fig. 5. The same as in Fig. 4, but for asymmetry parameter.

tical depth as demonstrated by Fig. 7, showing the optical depth as a function of $D_{\mathrm{e}, \max }$, and their non-consideration would result in a value of $\sim 0.33$ at $500 \mathrm{~nm}$, which is lower than $\sim 0.39$ for $D_{\mathrm{e}, \max }=50 \mu \mathrm{m}(+18 \%)$ and much lower compared to the value of $0.42(+27 \%)$ measured by Tesche et al. (2009) on 19 May 2006 about noon. Thus, the total size distributions have to be applied in realistic considerations.

We stress the role of the large dust particles not only because of their radiative effects (Otto et al., 2007; Solmon et al., 2008; McFarlane et al., 2009; Mallet et al., 2009), but especially with regard to the problem to retrieve them applying passive remote sensing techniques. For example, Kaufman et al. (2001) reported a negligible dust absorption and a $\varpi$ of $\sim 0.97$ in the visible spectrum. Dubovik et al. (2002) presented retrieval data of $\varpi(\lambda)$ over Cape Verde Islands and derived averaged values (years 1993-2000) of $\varpi(440 / 1020) \sim 0.93 / 0.99$ assuming spherical dust particles. Applying a similar retrieval method, but considering spheroidal particles, Ogunjobi et al. (2008) found smaller values of $\varpi(440 / 1020) \sim 0.89 / 0.93(-4.3 /-6.1 \%)$ over Cape Verde (years 1996-2003). Such relatively large values 


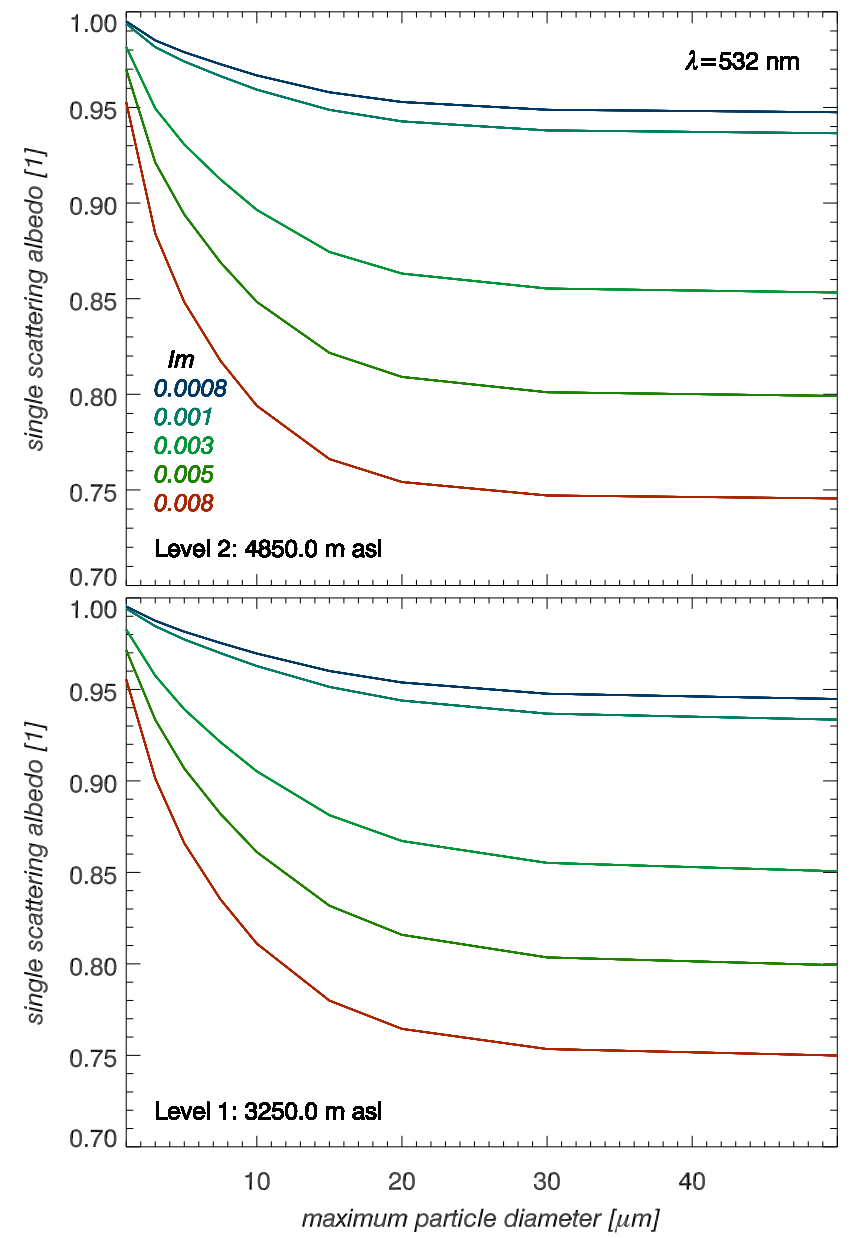

Fig. 6. The same as in Fig. 4, but for the single wavelength of $532 \mathrm{~nm}$ and as a function of the maximum particle diameter $D_{\mathrm{e}, \max }$ between 1 and $50 \mu \mathrm{m}$. The coloured curves represent various values of the size-constant imaginary part ("Im") of the complex refractive index. For the real part a size-constant value of 1.56 was applied (Otto et al., 2009).

of $\varpi$ in the solar range are in contrast to simulated values of $\sim 0.8$ at $550 \mathrm{~nm}$ based on in-situ data (Otto et al., 2007, 2009; Müller et al., 2010) and to dust models (Cattrall et al., 2003). These discrepancies demonstrate that further efforts have to be made in developing improved aerosol retrieval algorithms. Furthermore, the exploitation of passive polarimetric measurements may provide valuable information. First efforts have been made by $\mathrm{Li}$ et al. (2007) who found a value of $\sim 0.9$ at $550 \mathrm{~nm}$ for spherical coarse African mineral dust particles.

\subsection{Realistic size equivalence and particle shape}

Otto et al. (2009) simulated vertical profiles of dust backscatter coefficient and lidar ratio, assuming spheroidal particles of constant ARs in various cases of size equivalence, and

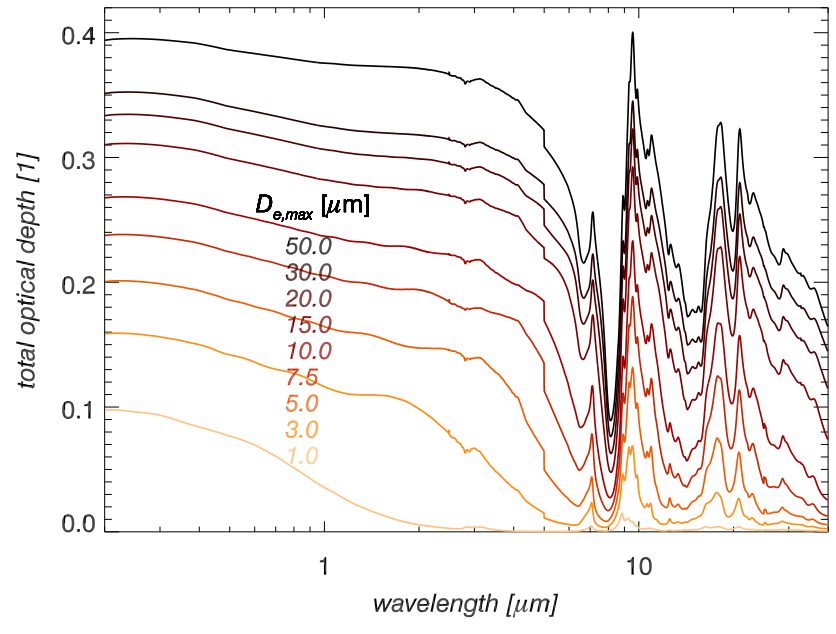

Fig. 7. Simulated spectral total optical depth of spherical mineral dust particles as measured on 19 May 2006 over OZT site about noon. Coloured curves represent various values of the maximum particle diameter $D_{\mathrm{e}, \max }$ between 1 and $50 \mu \mathrm{m}$ (see Fig. 4).

compared the results to measured lidar and sun photometer data. It turned out that volume equivalence and oblate model particles were most probable to fit the observations. However, these authors stated in their conclusions that the assumption of constant ARs for each model particle might be one solution only. Due to ambiguities the inversion of shape information from ensemble data of the optical properties does not have to be unique. Thus, we wish to consider a more realistic situation and extend these computations by considering measured AR distributions (Fig. 1). Our simulations are based on the same micro-physical particle data and are compared with the same lidar and sun photometer data as applied by Otto et al. (2009). An overview of the times of day, on 19 May 2006 over the OZT site, to that the measurement data refer is given next:

- Size distributions: 11:23-12:06 UTC (Weinzierl et al., 2009).

- Mean vertical profile of total number concentration: 10:50-12:20 UTC (Otto et al., 2009; Weinzierl et al., 2009).

- Mean total optical depth (sun photometer): 10:00-11:15 UTC (Tesche et al., 2009).

- Mean backscatter coefficient and lidar ratio (two independent lidars): 09:59-11:16 (Tesche et al., 2009) and 11:08-11:10 UTC (Esselborn et al., 2009).

Keeping in mind the assumptions made w.r.t. the treatment of spheroidal model particles (Sect. 3.2), Fig. 8 shows the simulated spectral total optical depth of the mineral dust plume as a function of particle shape, that is either prolate or oblate model spheroids, and size equivalence. Large 


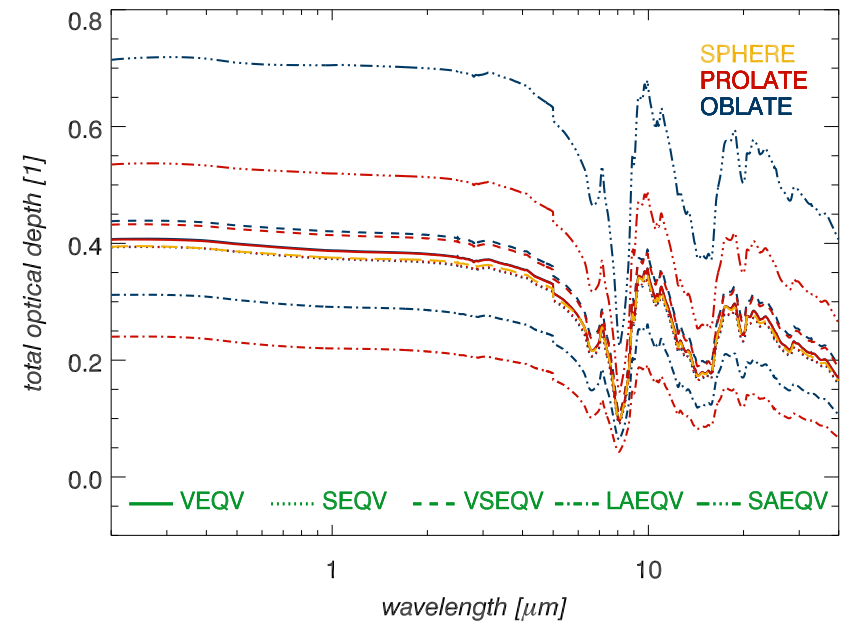

Fig. 8. Simulated spectral total optical depth of spherical (yellow) and spheroidal mineral dust particles as measured on 19 May 2006 over OZT site about noon. Either prolate (red) or oblate (blue) shapes were considered when averaging over the measured AR distributions (Fig. 1). Size equivalence cases were applied as discussed in Sect. 3.2.

differences in particle shape only occur for LAEQV and SAEQV, which both lead to unrealistically low and high optical depths. Thus, VEQV, SEQV and VSEQV remain as candidates for reasonably fitting the observations.

Figure 9 depicts simulated vertical profiles of the backscatter coefficient and lidar ratio compared to the lidar data, which are well-matched by both VEQV, SEQV and VSEQV, but in the case of prolate shape only. To derive the most probable size equivalence case we compared optical depths computed at $500 \mathrm{~nm}$ to the mean value measured by a sun photometer. The results a summarised in Table 1: prolate particles and the case of VSEQV lead to the smallest deviation. Hence best fit to the measurements carried out for one particular situation during SAMUM-1 is given by volume-tosurface equivalence and prolate particle shape. With regard to uncertainties in optical depth measurements and the relatively small deviations between the cases VEQV, SEQV and VSEQV for prolate shape, the lidar data together with the more realistic consideration of AR distributions enables us to state that at least prolate shape is more realistic than oblate.

These results of realistic size equivalence and particle shape, that is, volume-to-surface equivalence and prolate shape, are in contrast to previous results, that is, volume equivalence and oblate shape (Otto et al., 2009), however, where constant ARs for each model particle were assumed. This demonstrates explicitly the ambiguities w.r.t. free variables when ensemble optical property calculations involve the treatment of non-spherical particles, and that particle models beyond our simple spheroid approximation may lead to differing results.
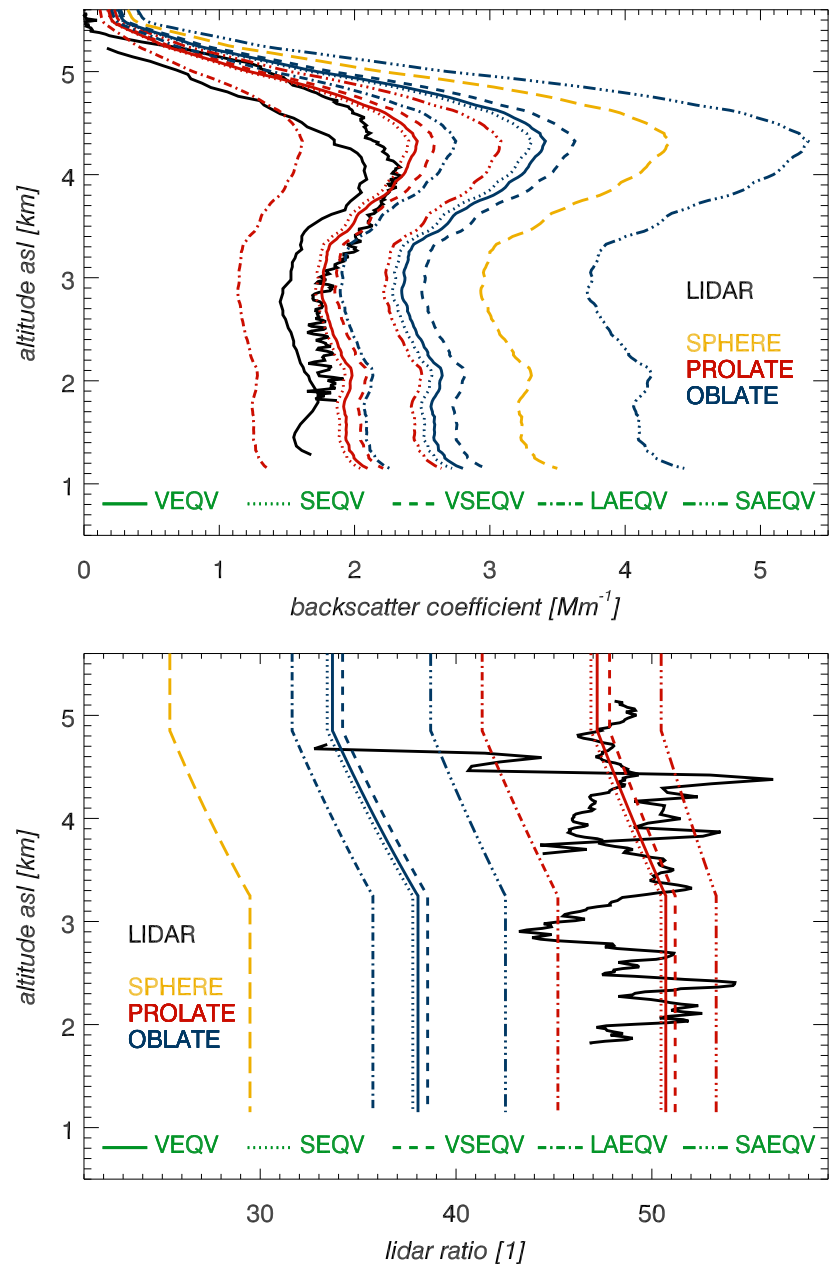

Fig. 9. The same as in Fig. 8, but for backscatter coefficient (top) and lidar ratio (bottom) at $532 \mathrm{~nm}$ compared to lidar data (black) as measured on 19 May 2006 over OZT site about noon (Sect. 2).

Table 1. Values of the optical depth simulated at $500 \mathrm{~nm}$ wavelength for the cases of size equivalence and particle shape of Fig. 8 and representative for the mineral dust observed on 19 May 2006 over OZT site about noon. The values in parentheses mean deviations to the respective mean value of $0.421 \pm 0.005$ measured via a sun photometer by Tesche et al. (2009).

\begin{tabular}{lrr}
\hline Spheres & $0.386(-8.28 \%)$ & \\
\hline Spheroids & oblate & prolate \\
VEQV & $0.400(-5.06 \%)$ & $0.398(-5.36 \%)$ \\
SEQV & $0.385(-8.47 \%)$ & $0.386(-8.27 \%)$ \\
VSEQV & $0.431(+2.31 \%)$ & $0.424(+0.82 \%)$ \\
LAEQV & $0.303(-28.0 \%)$ & $0.230(-45.24 \%)$ \\
SAEQV & $0.709(+68.5 \%)$ & $0.528(+25.43 \%)$ \\
\hline
\end{tabular}



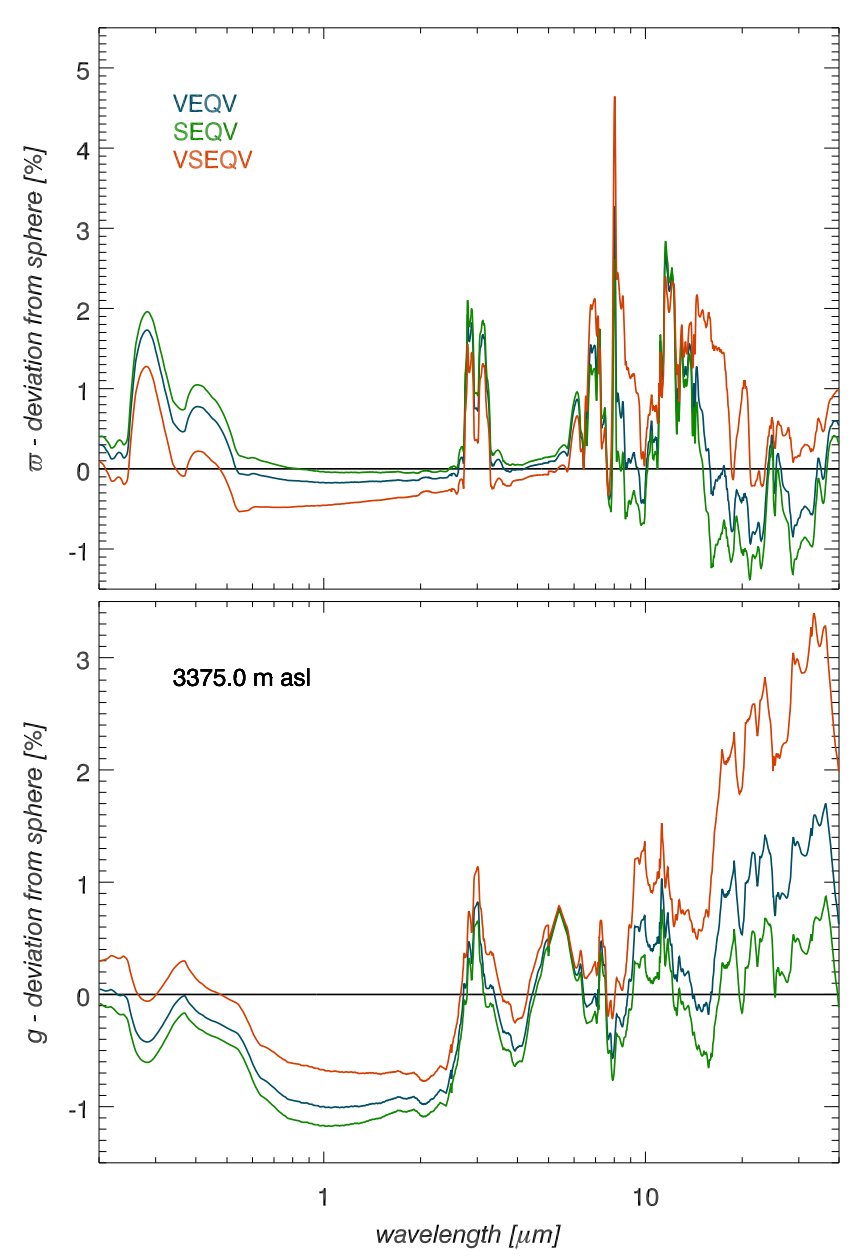

Fig. 10. Simulated percental deviations in the single scattering albedo (top) and asymmetry parameter (bottom) between prolate spheroidal and spherical model particles as a function of wavelength applying the measured AR distributions (Fig. 1). The full-spectral computations were performed assuming the size equivalence cases of VEQV (blue), SEQV (green) as well as VSEQV (red) and are representative for an altitude of $3375 \mathrm{~m}$ a.s.l. at the centre of the mineral dust plume as observed on 19 May 2006 over OZT site about noon.

\subsection{Non-sphericity effects}

Considering the realistic particle shape, prolate model spheroids, and averaging over the measured distributions of the AR (Fig. 1), we computed single scattering albedo and asymmetry parameter $g$ as well as absorption, scattering and extinction coefficient at $3375 \mathrm{~m}$ a.s.1. (2225 $\mathrm{m}$ above ground level) at the centre of the Saharan dust plume (observed on 19 May 2006 over the OZT site and extending from 1150 to $5600 \mathrm{~m}$ a.s.1.) and at the ground surface of OZT $(1150 \mathrm{~m}$ a.s.l.). Assuming also spherical model particles we calculated full-spectral deviations to the case of spheroidal ones. These are depicted in Figs. 10 and 11.

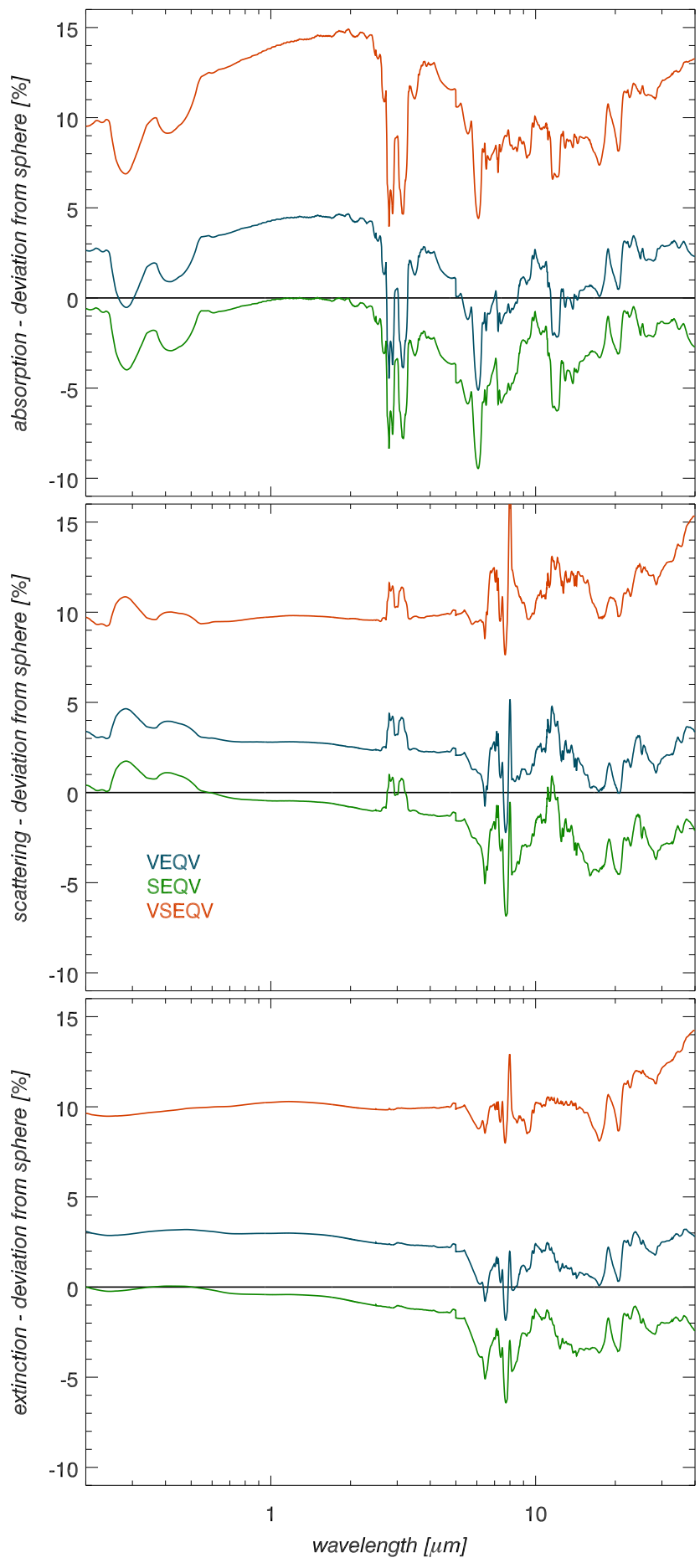

Fig. 11. The same as in Fig. 10, but for absorption (top), scattering (centre) and extinction coefficient (bottom) at ground level of OZT (1150 $\mathrm{m}$ a.s.1.).

The effects of the prolate particles on $\varpi$ and $g$ are relatively small (Otto et al., 2009). The respective spheroidal-spherical deviations are within $\sim \pm 1 \%$ in the 
solar and $\sim \pm 4 \%$ in the thermal spectral range where larger variabilities were found. Oblate particles, e.g., lead to larger differences in $g$ with a minimal value of $\sim-3 \%$ in the solar (not shown), illustrating that prolate particles are less backscattering than oblate ones (Otto et al., 2009). Moreover, the case of VSEQV that was found to be most realistic results in smallest/largest deviations in the solar/thermal region compared to the other two cases.

Significant spheroidal-spherical deviations may be found in the absorption, scattering and extinction coefficient with largest values for the case of VSEQV of about $10 \%$ over the entire spectral range.

\section{Radiative effects}

To demonstrate the radiative effects of Saharan mineral dust we treated the dust layer, observed on 19 May 2006 over OZT site about noon, to be located directly over an elevated land surface (OZT-like, $z=1150 \mathrm{~m}$ a.s.l.) and as a lifted layer over an ocean surface $(z=0 \mathrm{~m}$ a.s.l.) whereas the latter case describes the situation of long-range transport of the dust over the Atlantic ocean. Both ground types are represented by a mean surface albedo (Fig. 3, top and bottom). For detailed information about these two scenarios and the radiative transfer model settings see Sect. 3.6.

Figures 12 and 13 each show the upward (top panel) and downward (bottom panel) spectral irradiances at the TOA and BOA whereas the former figure represents the dust over land and the latter one the dust over ocean. The dust particles are treated to be spherical as well as spheroidal ones of prolate and oblate shape assuming size equivalence cases of VSEQV and VEQV, respectively. The scenario of oblate particles and VEQV represents the shape properties, which were found to be most realistic in a previous paper (Otto et al., 2009). But note that these authors considered constant ARs for each model particle in contrast to our more realistic consideration of measured AR distributions and VSEQV. Each top and bottom panel of the two figures also shows spectral percental deviations in the irradiances, always compared to the case of a clear-sky atmosphere ("No Dust").

Considering the downward component at the BOA (bottom panels) it turns out that both over land and ocean the solar radiation is significantly reduced due to the presence of the dust compared to clear sky, while there is an enhancement in the thermal irradiances. These effects are larger in the land ( $\Delta$ up to $-35 \%$ in the solar and up to $+300 \%$ in the thermal spectral range) than in the ocean case ( $\Delta$ up to $-30 \%$ in the solar and up to $+30 \%$ in the thermal range) and larger in the thermal than in the solar region. Both demonstrates the influence of the surface albedo, which is higher for land, in combination with the dust, and that direct ground-based radiometric measurements to detect minderal dust should rather be performed at the thermal window region.
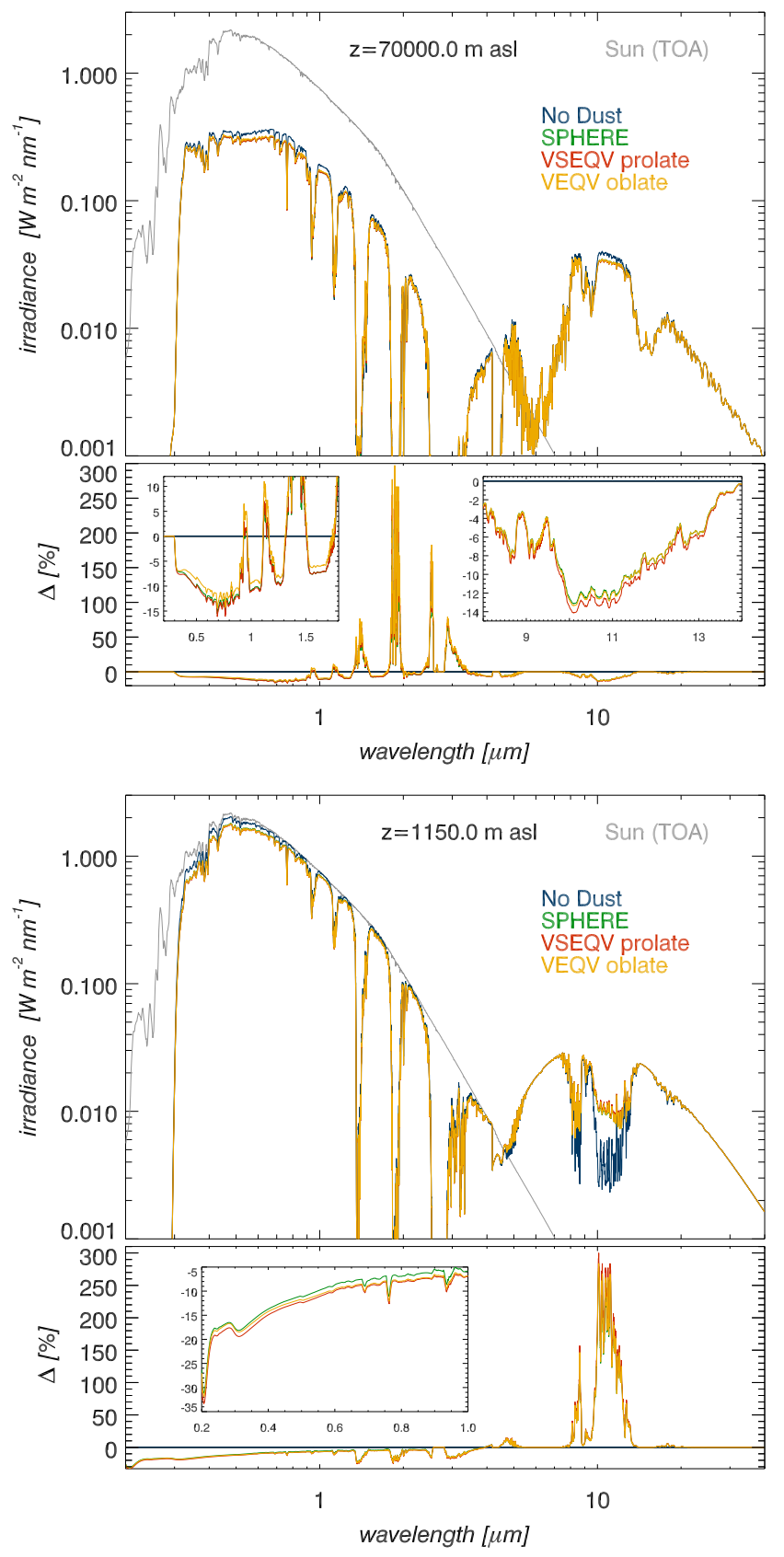

Fig. 12. Simulated solar and thermal irradiances, representative for the mineral dust plume observed on 19 May 2006 over OZT site about noon and considered directly over a mean land surface (Fig. 3, top), for spherical (green), prolate (VSEQV, red) and oblate (VEQV, yellow) spheroidal model particles. $\Delta$ represents the deviations to the case of a dust-free atmosphere (blue). (top) Upward part at the TOA $(z=70 \mathrm{~km}$ a.s.1.) and (bottom) downward part at the BOA (OZT, $z=1.15 \mathrm{~km}$ a.s.1.). The solar incident irradiance at the TOA is indicated by grey curves. The simulations were performed for a solar zenith angle of $0^{\circ}$. 

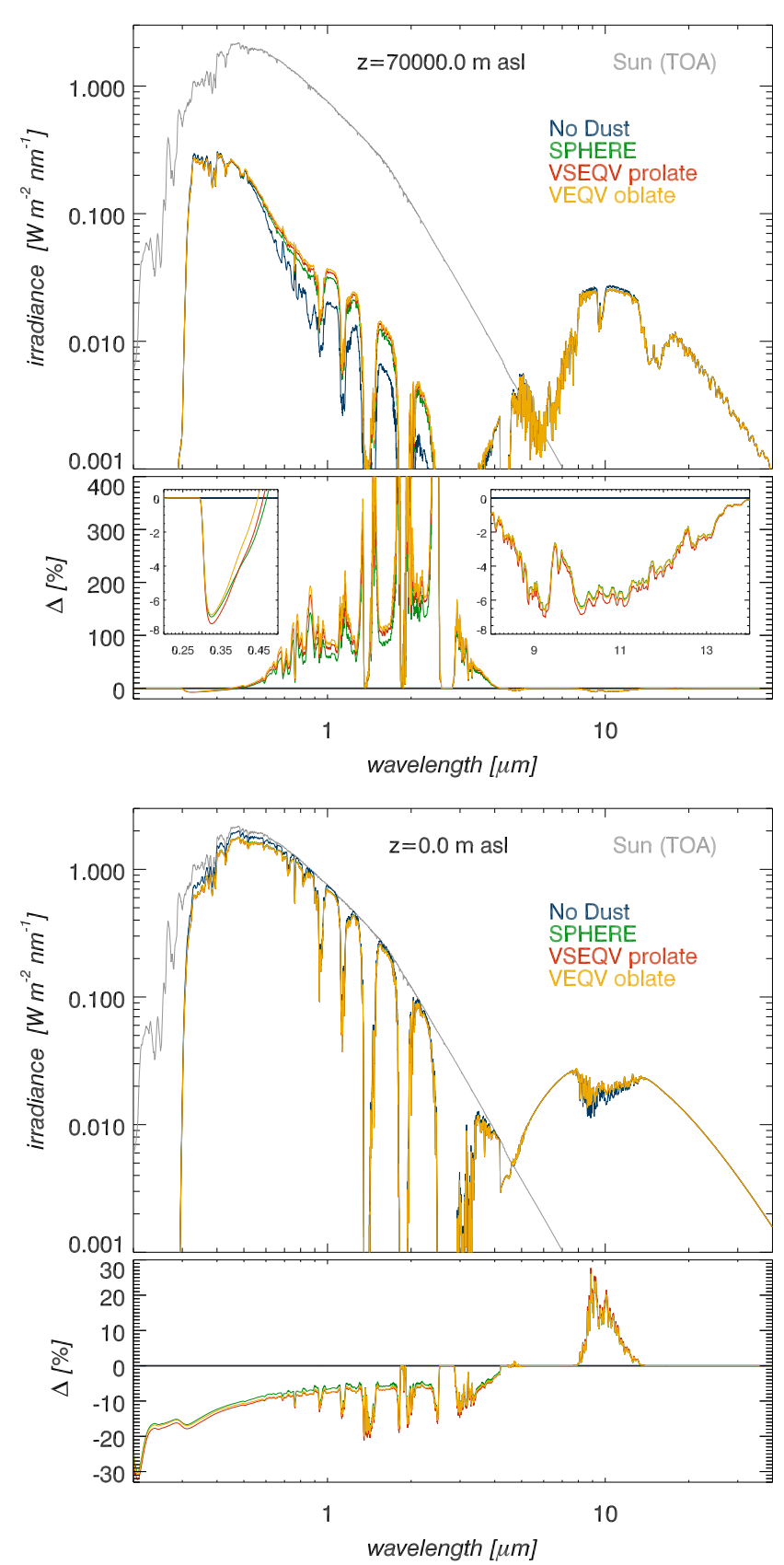

Fig. 13. The same as in Fig. 12, however, for the situation of the observed mineral dust plume, which is now lifted over a mean ocean surface (Fig. 3, bottom) and whose lower boundary is located at $z=1.15 \mathrm{~km}$ a.s.l. whereby the BOA is represented by sea level $(z=$ $0 \mathrm{~m}$ a.s.l.).

At the TOA the mineral dust causes qualitatively the same effects in the thermal range: the upward irradiance is reduced both over land and ocean, that is, terrestrial emission from the Earth-atmosphere system to space is inhibited whereas the effects over land ( $\Delta$ up to $-14 \%$ ) are twice as in the case of dust over ocean ( $\Delta$ up to $-7 \%$ ) due to the higher surface temperature of the land (Sect. 3.6) emitting a larger amount of radiation that can be absorbed. In the solar spectral range the mineral dust causes, apart from the absorption band regions, a significant reduction of the upwardly transferred radiation over land ( $\Delta$ up to $-15 \%$ ), while the radiation loss of the Earth-atmosphere system is significantly forced for the ocean scenario ( $\Delta$ is negative for wavelengths lower than $\sim 450 \mathrm{~nm}$ only, but becomes significantly positive for larger wavelengths).

All these radiative effects reported are forced by the prolate dust particles, since the absolute value of $\Delta$ is larger than in the case of spherical particles for most of the wavelengths considered. Oblate model particles act more backscattering than prolate ones, since the respective $\Delta$ is always larger at the TOA. Moreover, particle non-sphericity leads to relatively small changes in the irradiance of $|\Delta| \sim 2 \%$ for most situations. Larger deviations only occur (1) in the downward radiation at the BOA for dust over land (Fig. 12, bottom panel) at the window region and (2) in the upward radiation at the TOA for dust over ocean (Fig. 13, top panel) in the mid-infrared spectral region ( $\sim 0.7$ to $3 \mu \mathrm{m}$ wavelength).

Thus, subject to the sensitivities found above, nonsphericity information might be retrieved by ground-based radiometric measurements over land but rather by satellitebased observations over ocean if the measurement accuracy is sufficient for both strategies. For example, Otto et al. (2009) reported uncertainties of about $3 \%$ in the solar irradiance measurements and of $5 \%$ in the solar-surface-albedo data (Bierwirth et al., 2009). Compared to our $\Delta$ computations such a measurement accuracy is not sufficient for constraining particle non-sphericity of mineral dust particles compared to simulations. The consideration of radiances or polarimetric measurements might be more promising, since larger sensitivities may be expected (Li et al., 2007).

\section{Radiative budget calculations}

Following Eqs. (1-3) we computed solar, thermal and total forcings (Sect. 3.4) of the Saharan mineral dust plume, observed on 19 May 2006 over OZT site about noon, over a mean land and ocean surface (Sect. 3.6) assuming spherical dust particles. To demonstrate the influence of particle nonsphericity on the dust forcing we treated the dust particles to be spheroids (Sect. 3.2).

\subsection{Spherical particles - the role of large particles}

We wish to study the effect of large (spherical) dust particles on the dust forcing by integrating the single particle optical properties over the measured size distributions up to various maximum diameters $D_{\mathrm{e}, \max }$ (Sect. 4.1). Figure 14 shows solar, thermal and total forcings at TOA (top), directly above the plume (centre) and at the BOA (bottom) as a function of $D_{\text {e, } \max }$. 


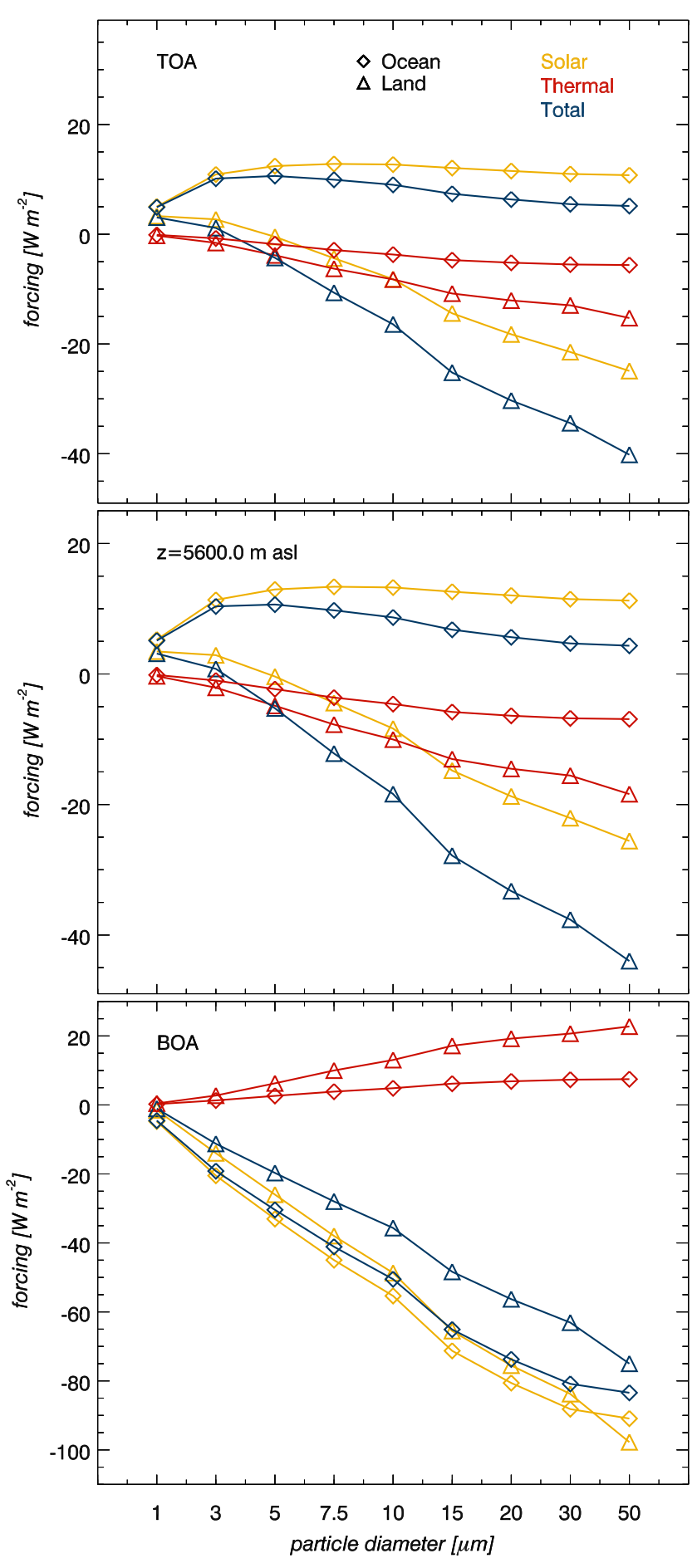

Fig. 14. Simulated solar, thermal and total forcings of the mineral dust plume, observed on 19 May over OZT site about noon, over a mean land and ocean surface as a function of the maximum particle diameter $D_{\mathrm{e}, \max }$ (Sect. 4.1) assuming spherical model particles. For computational details see Sects. 3.4 and 3.6. (top) $\Delta F$ (TOA), (centre) $\Delta F(z)$ at the upper boundary of the dust layer at an altitude of $z=5.6 \mathrm{~km}$ a.s.l. and (bottom) $\Delta F(\mathrm{BOA})$.
At the BOA $\Delta F(\mathrm{BOA})$ is always negative in the solar spectral range. Due to absorption of radiation the dust causes a reduction of the downward solar radiation both over land and ocean (Sect. 5). The larger $D_{\mathrm{e}, \max }$ is, the stronger is this decrease. For both surface types and $D_{\mathrm{e}, \max }=50 \mu \mathrm{m}$ similar values of $\Delta F(\mathrm{BOA})$ of about $-90 \mathrm{~W} \mathrm{~m}^{-2}$ were obtained. The opposite is the case in the thermal region. Due to emission of radiation the dust always causes a positive thermal forcing at the BOA with a value of about $+22.5 \mathrm{~W} \mathrm{~m}^{-2}$ for $D_{\text {e, } \max }=50 \mu \mathrm{m}$ over land, which is significantly larger than the $+7.5 \mathrm{~W} \mathrm{~m}^{-2}$ over ocean. The total effect is negative indicating a cooling at the ground surface, since a significant fraction of the radiation, penetrating the dust layer, is absorbed. Increasing particle size enhances this effect.

At the TOA $\Delta F(\mathrm{TOA})$ is always negative in the thermal spectral range. This means a reduction of thermal radiation that leaves Earth to space. The dust acts as a source of radiation in downward direction by inhibiting thermal emission in upward direction (Sect. 5). This warming effect is the larger the larger $D_{\mathrm{e}, \max }$ is and is more significant over land. In the solar range $\Delta F($ TOA $)$ is positive both over ocean and land for small values of $D_{\mathrm{e}, \max }<5 \mu \mathrm{m}$, which corresponds to a solar cooling of the Earth-atmosphere system. However, for increasing $D_{\mathrm{e}, \max }$ larger than approximately $5 \mu \mathrm{m}$, the forcing remains relatively constant in the case of ocean while it decreases dramatically in the case of the dust over land whereas it becomes negative. That is, the solar forcing of mineral dust over an ocean surface is always positive (solar cooling) but may be either positive or negative (solar warming) depending on the dust particle size. Qualitatively the same can be stated for the total dust forcing with values of about $5 \mathrm{~W} \mathrm{~m}^{-2}$ and a total cooling in the ocean as well as values of about $-40 \mathrm{~W} \mathrm{~m}^{-2}$ and a total warming in the land case (for $D_{\mathrm{e}, \max }=50 \mu \mathrm{m}$ ). Only slight changes in the forcings occur at the top of the dust layer compared to the TOA.

\subsection{Spheroidal model particles}

We wish to study the influence of the particle non-sphericity on the dust forcing. Considering the Saharan mineral dust plume, observed on 19 May 2006 over OZT site about noon over a mean land and ocean surface, Fig. 15 depicts the solar dust forcings (left) at the TOA (top) and BOA (bottom) for spherical (Mie) and spheroidal model particles, which are treated to be of prolate (red) and oblate (blue) shape in various cases of size equivalence (LAEQV, SAEQV, SEQV, VEQV and VSEQV). Compared to the case of spheres we calculated percental changes of forcing in all the cases of particle non-sphericity (right) whose effects we wish to quantify. The same was done for thermal (Fig. 16) and total spectral range (Fig. 17).

In the solar range the dust forcing at the TOA is always positive in the ocean case but negative in the land case. This corresponds to a cooling and warming of the Earthatmosphere System, respectively. Prolate dust particles are 

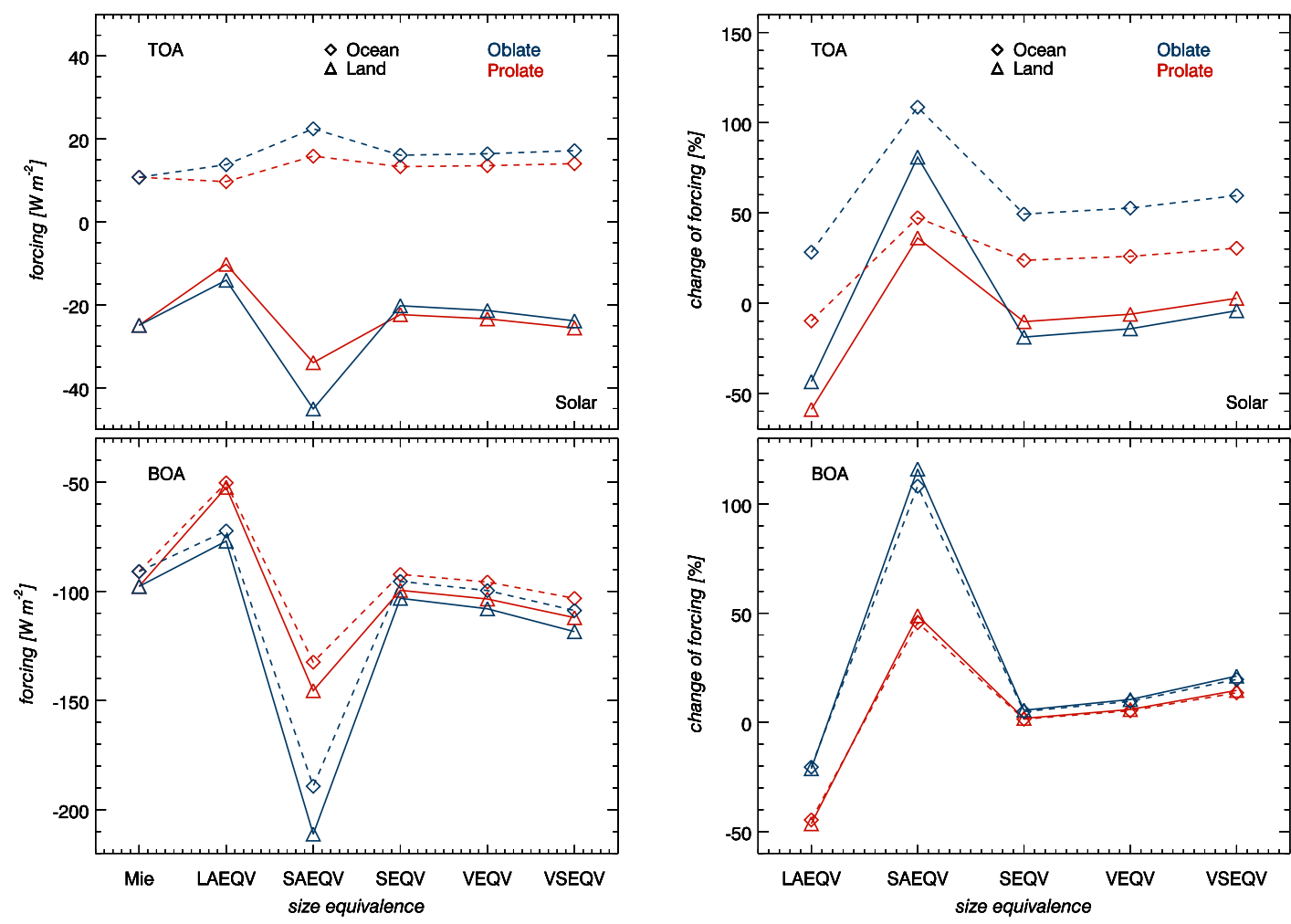

Fig. 15. Simulated solar forcings of Saharan mineral dust (left) and changes of forcing caused by spheroidal particles compared to sphercial ones (right) at the TOA (top) and BOA (bottom) over a mean land and ocean surface. See main text for details.
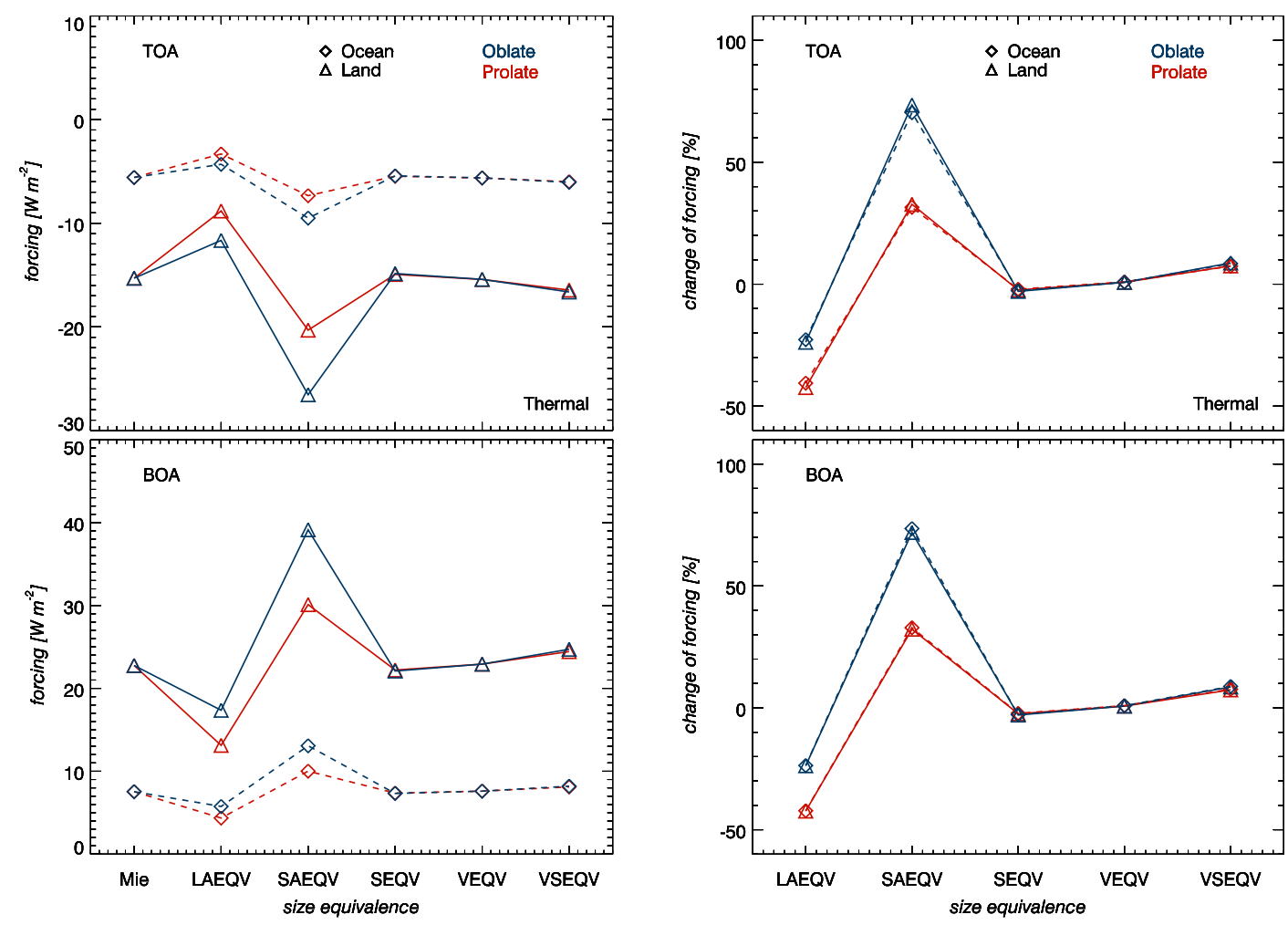

Fig. 16. The same as in Fig. 15, but for thermal spectral range. 


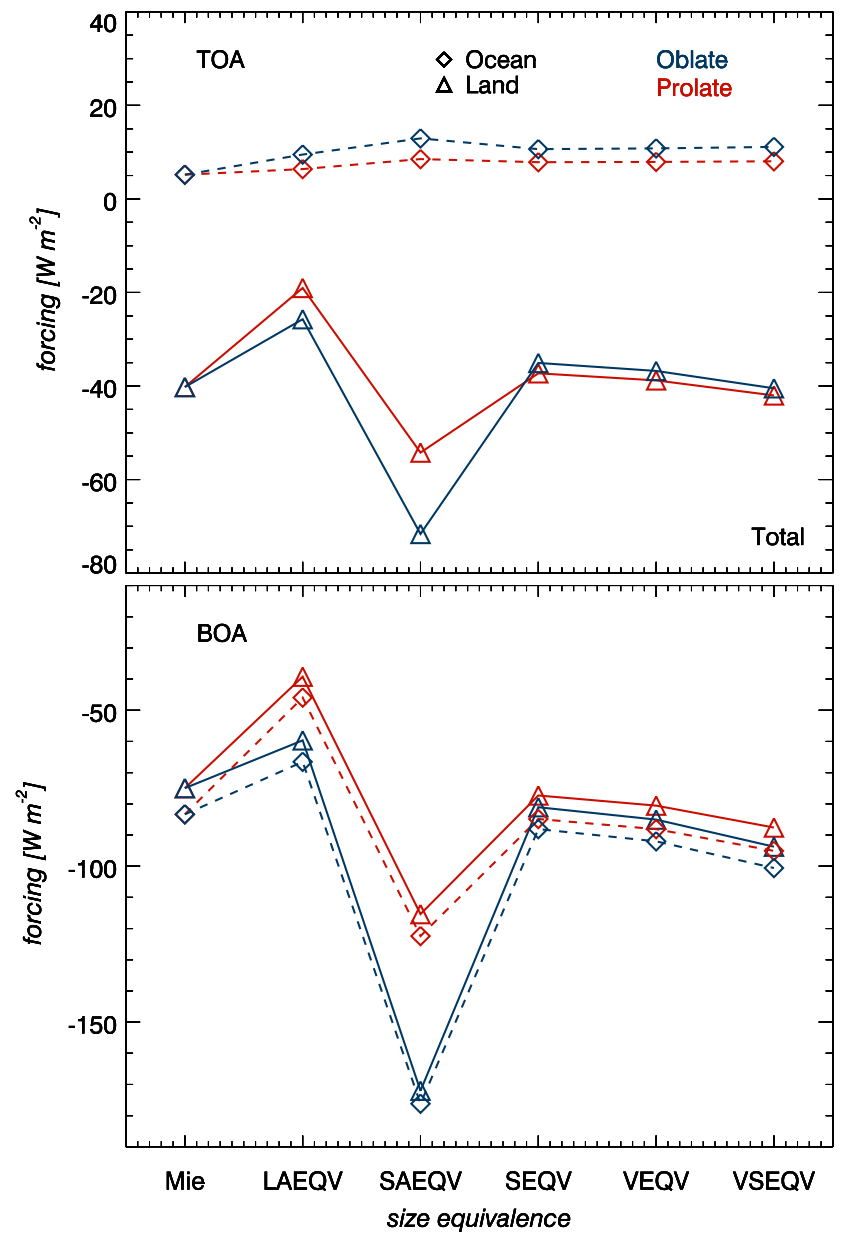

Fig. 17. The same as in Fig. 15, but for entire (total) spectral range.

always less backscattering than oblate ones for the rather realistic cases of SEQV, VEQV und VSEQV. Compared to spherical particles only a slight change of forcing is found for prolate shape and VSEQV in the land scenario, but a value of $30 \%$ in the case of the dust over ocean. At BOA always negative dust forcings occur representing the loss of downward radiation. This reduction is enhanced by both prolate and oblate spheroidal particles in cases of SEQV, VEQV und VSEQV up to a maximum value of about $20 \%$.

In the thermal range the dust forcing is always negative at the TOA and positive at the BOA whereas these effects are more significant in the case of dust over land. Thus, mineral dust inhibits the emission of thermal radiation to space. For the cases SEQV, VEQV and VSEQV differences between prolate and oblate shape are negligible. Comparing VSEQV to Mie theory, this case of non-sphericity increases the forcing at both TOA and BOA by about $10 \%$.

Total dust forcing is qualitatively comparable to the findings in the solar range: positive/negative values at the TOA over ocean/land, indicating a cooling/warming of the Earth-
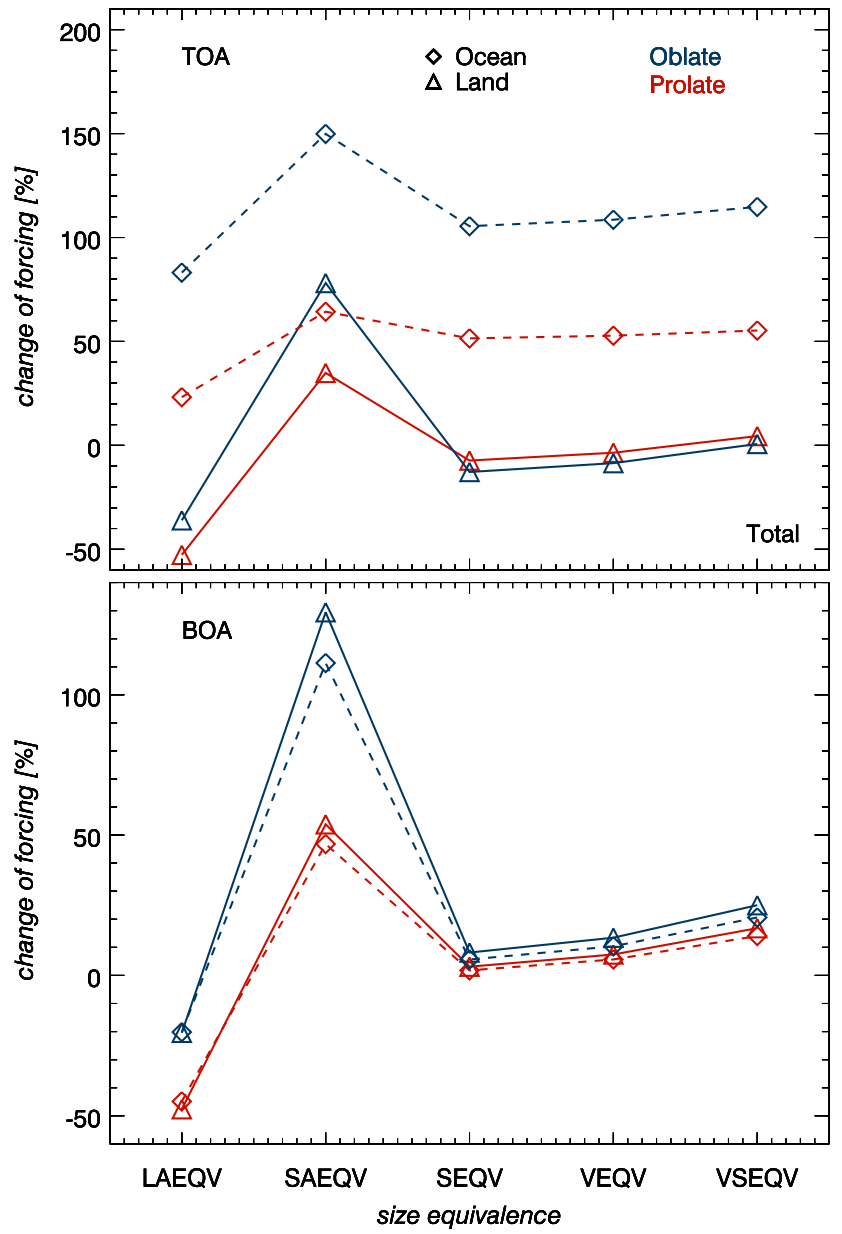

atmosphere system, and always negative values at the BOA. Assuming spherical dust particles their forcing at the TOA amounts to about $5 \mathrm{~W} \mathrm{~m}^{-2}$ and $-40 \mathrm{~W} \mathrm{~m}^{-2}$ over ocean and land, respectively, while dust forcing at the BOA is approximately $-80 \mathrm{~W} \mathrm{~m}^{-2}$ for both surface types. Comparing these values to the respective forcings of realistic non-spherical particles, that is, VSEQV and prolate spheroids (Sect. 4.2), the changes of forcing due to particle non-sphericity are given next:

- $55 \%$ at the TOA over ocean: the back scatter and cooling effect of the Earth-atmosphere system is enhanced.

- $5 \%$ at the TOA over land: the influence of particle nonsphericity is weak.

- $15 \%$ BOA both over land and ocean: the decrease of downward radiation is forced.

These changes of forcing, due to the realistic consideration of particle non-sphericity presented above, seem to be quite large compared to the changes in the respective irradiances 
in Figs. 12 and 13. For example, in the solar spectral range and at the TOA (top figures) the deviations between the red ("VSEQV prolate") and green ("SPHERE") curves amount less than $20 \%$ whereas in the visible range these differences are even smaller of about $2 \%$ (Sect. 5). Such small values correspond to simulations of changes in dust layer reflectivity due to the use of spheroidal dust particles instead of spherical ones as performed by Fu et al. (2009) at $550 \mathrm{~nm}$ wavelength for a non-reflecting ground surface as in the case of an ocean. These authors found that the relative errors in the reflectivity due to spherical approximation (SA) are always less than 5\% compared to the non-spherical approximation (NSA) dealing with model spheroids. Regarding Fig. 13 (top), that is, the upwardly transferred radiation at the TOA in the solar spectral range $I_{\Delta \lambda}$ from 0.2 to $4 \mu \mathrm{m}$ wavelength in the case of mineral dust over a typical ocean surface, we see that a mean spectral deviation of $5 \%$ between the red and green curve might be realistic. With the help of this constant deviation we may estimate the change of forcing induced by NSA compared to SA as follows.

With regard to Sect. 3.4 and Eq. (2) we may introduce $\Delta F_{\mathrm{SA}}(\mathrm{TOA})$ and $\Delta F_{\mathrm{NSA}}(\mathrm{TOA})$, that is, the forcings at the TOA for spherical and spheroidal (prolate shape and VSEQV) model particles, respectively. Since $F_{+}^{r}(\mathrm{TOA}, \lambda)$ is equal in both cases we may write

$$
\begin{aligned}
& \Delta F_{\mathrm{NSA}}(\mathrm{TOA})-\Delta F_{\mathrm{SA}}(\mathrm{TOA}) \\
& \quad=\int_{I_{\Delta \lambda}}\left[F_{+, \mathrm{NSA}}(\mathrm{TOA}, \lambda)-F_{+, \mathrm{SA}}(\mathrm{TOA}, \lambda)\right] d \lambda .
\end{aligned}
$$

Assuming $F_{+, \mathrm{NSA}}(\mathrm{TOA}, \lambda):=c F_{+, \mathrm{SA}}(\mathrm{TOA}, \lambda)$ we find

$$
\begin{array}{r}
\Delta F_{\mathrm{NSA}}(\mathrm{TOA})-\Delta F_{\mathrm{SA}}(\mathrm{TOA}) \\
=(c-1) \underbrace{\int_{I_{\Delta \lambda}} F_{+, \mathrm{SA}}(\mathrm{TOA}, \lambda) d \lambda .}_{=: \mathcal{F}_{+, \mathrm{SA}}} .
\end{array}
$$

The change of forcing in units of $\%$ may then be written as

$$
\begin{aligned}
\frac{\Delta F_{\mathrm{NSA}}(\mathrm{TOA})-\Delta F_{\mathrm{SA}}(\mathrm{TOA})}{\Delta F_{\mathrm{SA}}(\mathrm{TOA})} \cdot 100 \% \\
=\frac{(c-1) \mathcal{F}_{+, \mathrm{SA}}}{\Delta F_{\mathrm{SA}}(\mathrm{TOA})} \cdot 100 \%=: \delta .
\end{aligned}
$$

For our estimation we assume the mean positive five percent deviation, that is, $c=1.05 . \Delta F_{\mathrm{SA}}$ (TOA) can be read off in Fig. 15 (top, left, "Mie") yielding a value of about 11 $\mathrm{W} \mathrm{m}{ }^{-2}$, while $\mathcal{F}_{+, \text {SA }}$ was calculated to amount $89.7 \mathrm{~W} \mathrm{~m}^{-2}$, which is of the same order of magnitude as computed by Otto et al. (2007) for a comparable situation of Saharan mineral dust over the Canary Islands who presented a value of $121.1 \mathrm{~W} \mathrm{~m}^{-2}$ in the solar range for their reference case (see their Table 4), already containing the measured dust approximated by spherical particles. With the help of these numbers we obtain a change of solar forcing at the TOA for the dust over ocean of

$$
\delta=\frac{0.05 \cdot 89.7}{11} \cdot 100 \% \approx 41 \%
$$

when dealing with spheroids of realistic prolate shape and volume-to-surface equivalence instead of spherical particles. The exact computation yield a value of about $30 \%$ (Fig. 15, top, right). This demonstrates that relatively small mean spectral deviations of about $5 \%$ in the irradiances between NSA and SA do not automatically translate to an also only five percent change in the dust forcing. Obviously, small spectral irradiance variations due to particle non-sphericity may sum to larger changes of forcing. Thus, the neglect of particle non-sphericity in radiative forcing calculations may lead to significant errors.

\section{Heating effects}

Prolate spheroidal particle shape was found to be realistic for the particles of the Saharan mineral dust plume observed on 19 May 2006 over OZT site about noon (Sect. 4.2). It also turned out that the dust layer causes a strong reduction of downward solar radiation at the BOA (Sects. 5 and 6). In the case of the dust over a mean land surface the upward component at the TOA is also diminished. In the thermal window region the dust inhibits the transmission of radiation to space. Thus, we expect significant radiative heating within the dust plume. Therefore we computed heating effects $\Delta H(z)$ by Eq. (4) assuming spherical dust particles and simulated changes of heating effect when dealing with prolate spheroidal model particles compared to the spheres (Sect. 3.5). Again we assume the dust layer to be located over a mean land and ocean surface (Sect. 3.6).

Figure 18 displays $\Delta H(z)$ for the measured dust over land for the solar (top), thermal (centre) and total (bottom) spectral range and various models of prolate spheroids (size equivalence cases LAEQV, SAEQV, SEQV, VEQV and VSEQV), while Fig. 19 depicts the same but for the dust over ocean (lifted layer extending from 1.15 to $5.6 \mathrm{~km}$ altitude a.s.l.). Since the dust absorbs solar radiation and blocks thermal emission to space, always positive values of the heating effect are obtained in the solar as well as negative and positive ones in the thermal range within the upper and lower altitude range of the dust plume, respectively, which is qualitatively independent of the underlying reflecting surface (land or ocean). In sum this yields total heating effects, which are always positive meaning a heating of the atmosphere within the dust layer. Moreover, this demonstrates that the warming impact of the land and the cooling impact of the ocean surface, caused by different surface temperatures and spectral surface albedos, is forced and alleviated by the dust.

The changes of the total heating effects caused by prolate spheroidal dust particles compared to spheres are shown Fig. 20. Size equivalence is varied when considering the dust 

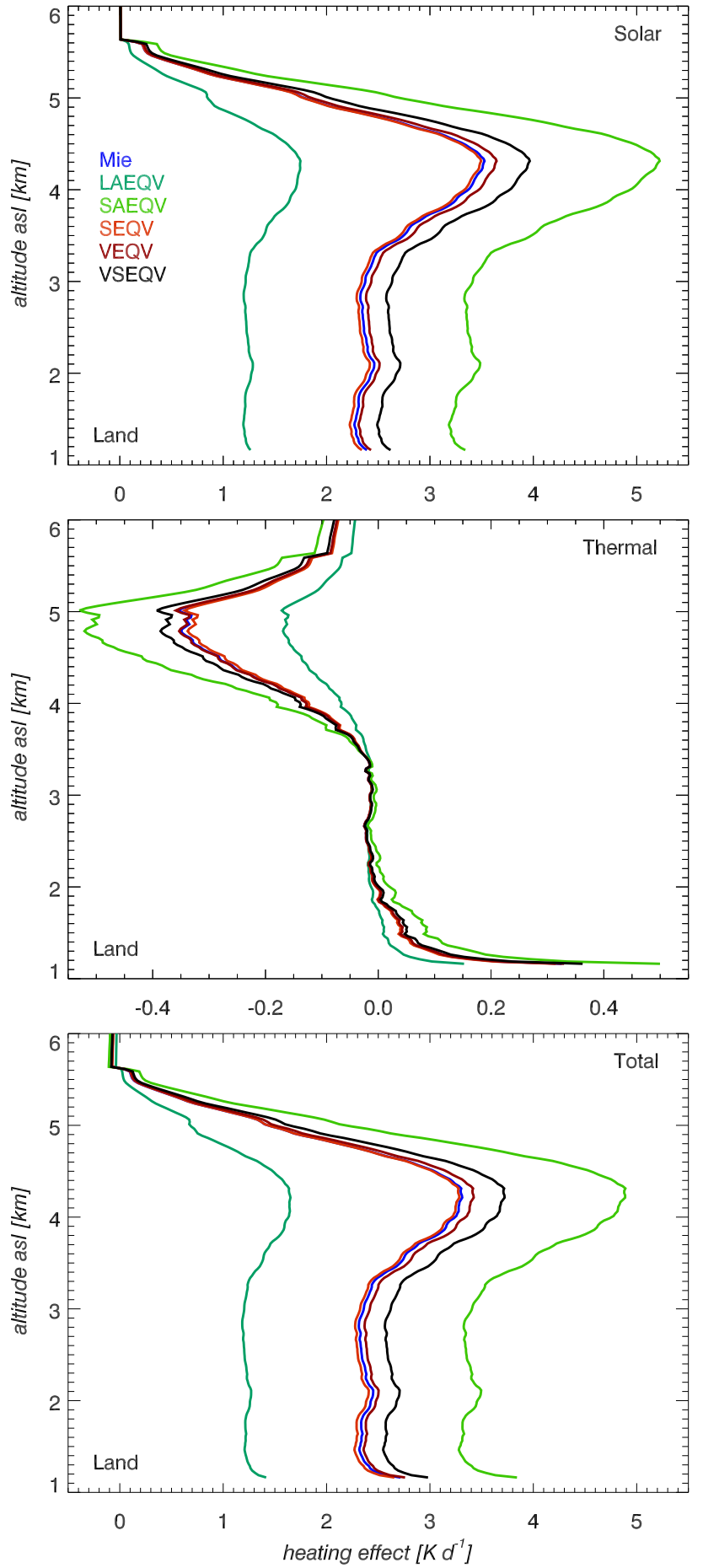

Fig. 18. Simulated heating effects $\Delta H(z)$ by Eq. (4) of the Saharan mineral dust plume, observed on 19 May 2006 over OZT site about noon, over a mean land surface assuming spherical (Mie) and prolate spheroidal model particles for various cases of size equivalence (LAEQV, SAEQV, SEQV, VEQV and VSEQV), representative for solar (top), thermal (centre) and total (bottom) spectral range.
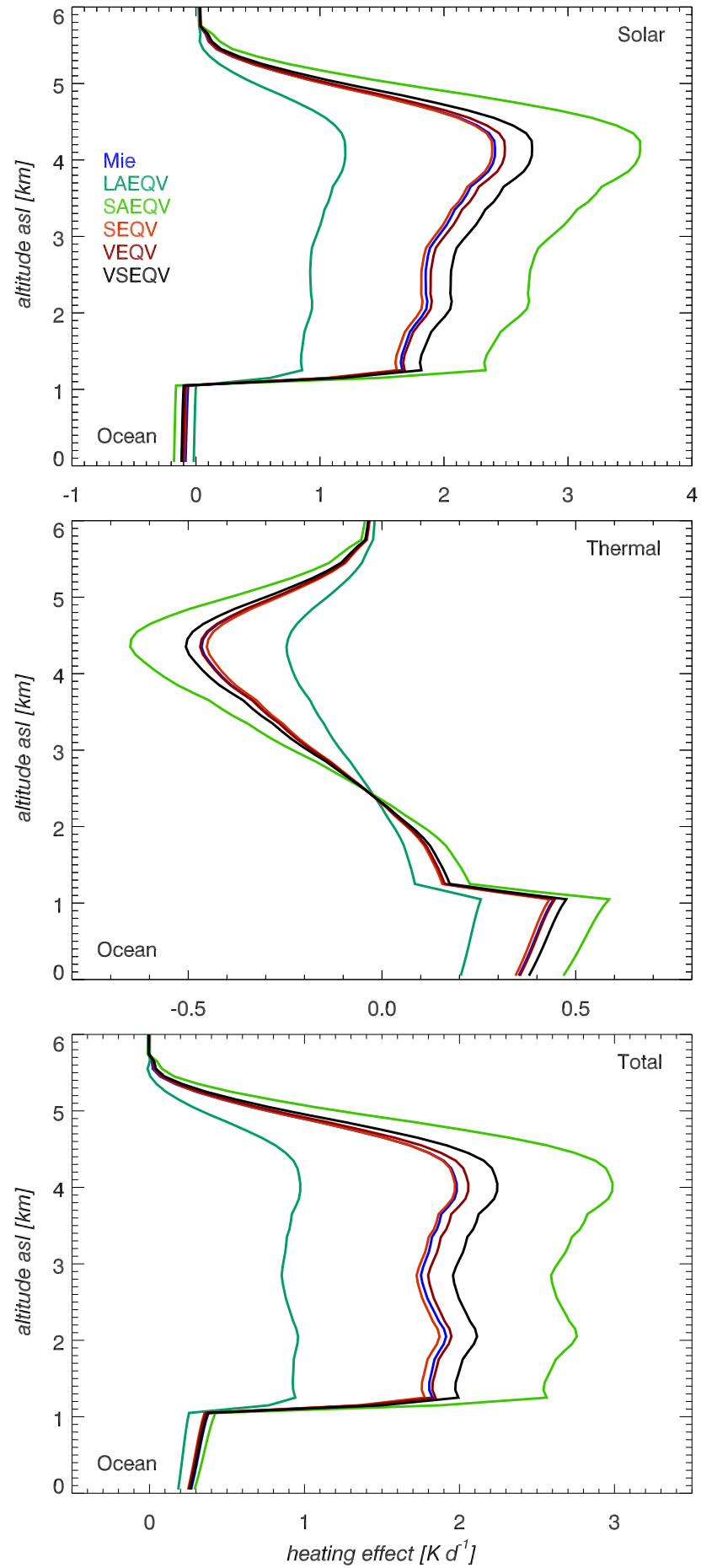

Fig. 19. Simulated heating effects $\Delta H(z)$ by Eq. (4) of the Saharan mineral dust plume, observed on 19 May 2006 over OZT site about noon, lifted over a mean ocean surface assuming spherical (Mie) and prolate spheroidal model particles for various cases of size equivalence (LAEQV, SAEQV, SEQV, VEQV and VSEQV), representative for solar (top), thermal (centre) and total (bottom) spectral range. 

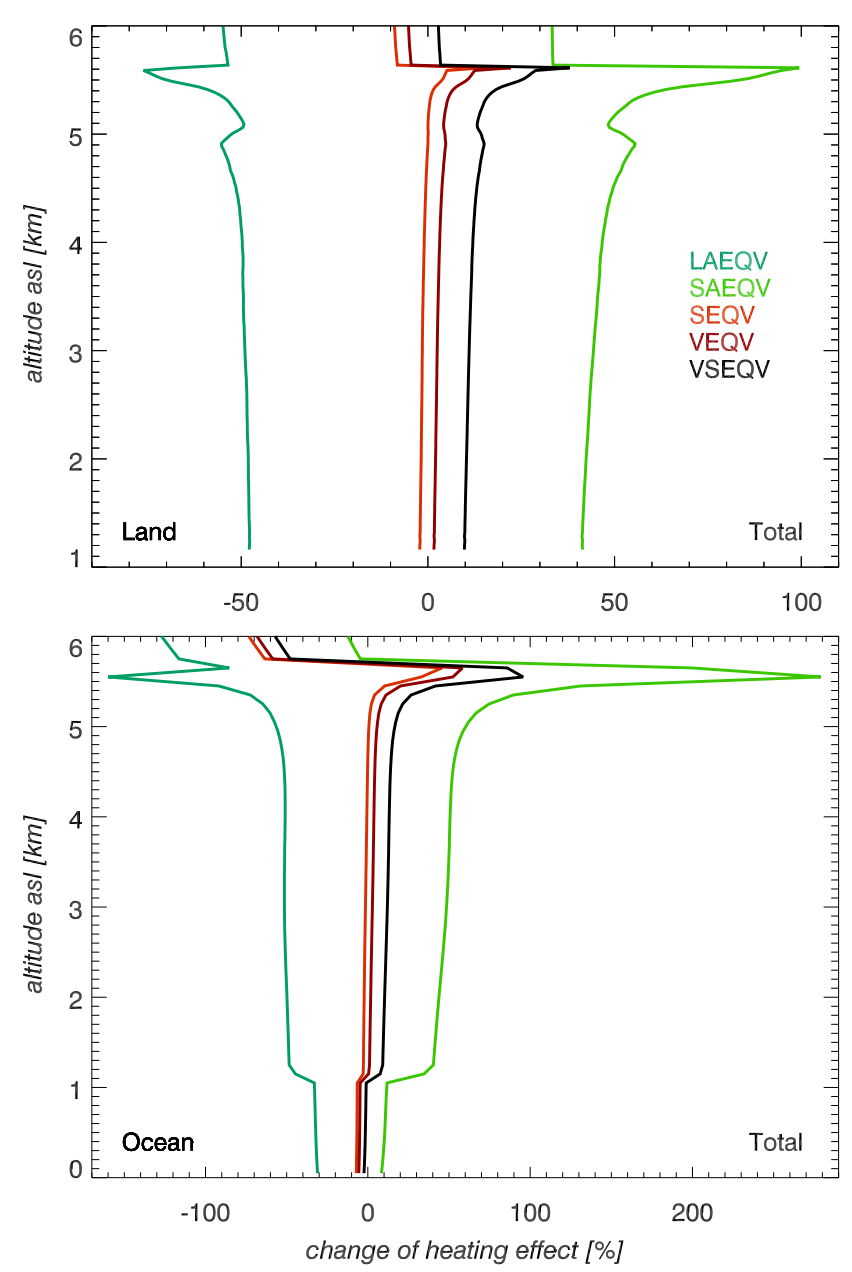

Fig. 20. Changes of total heating effect $\Delta H(z)$ of the Saharan mineral dust plume, observed on 19 May 2006 over OZT site about noon, caused by prolate spheroidal particles compared to spherical ones, assuming various cases of size equivalence (LAEQV, SAEQV, SEQV, VEQV and VSEQV). Mineral dust over a mean land (top) and ocean surface (bottom).

ensemble over land and ocean. For the most realistic case of volume-to-surface equivalence (VSEQV), as it turned out in Sect. 4.2, the non-sphericity of the dust particles increases the heating impact of the dust by

- 10 and $20 \%$ at lower and upper altitude range of the dust layer over both surface types.

Hence, the non-sphericity of the dust particles causes a non-negligible impact on the radiative heating, which might be important for the dynamics in the troposphere and Earth's climate keeping in mind that Saharan mineral dust is transported over long distances from North Africa westwards to America.

\section{Conclusions}

This study of the radiative impact of Saharan mineral dust close to the source region represents one single measurement day during SAMUM-1 only. To extend the results data of additional campaign days may be considered.

Large mineral dust particles have a big influence on the radiative impact of the dust. This necessitates more careful ground- and aircraft-based measurements of coarse aerosol particles. Beyond, the consideration and quantification of the two independent quantities "particle shape" and optical "size equivalence" in size distribution measurements are important for accurately modelling the radiative impact of aerosols (and clouds). In principle, this holds for all measurements, which involve particle sizing, e.g., the determination of the chemical composition as a function of particle size. Note that the two quantities maybe different for size distribution and chemical composition measurements. Additionally, both may also vary with particle size depending on the applied measurement techniques. We did not consider such complex cases, however, we demonstrated that experimental information about these two quantities are highly important for optical modelling purposes. Our results might also be of interest for the interpretation of size measurements of cloud elements and accurate modelling their optical properties within the scope of fast parameterisations: is the usually applied equivalence assumption of "maximum dimension" correct?

Our concept to consider micro-physical particle data as a starting point has successfully been applied. Such treatment requires assumptions w.r.t. the spectral complex refractive index (SCRI). A simple volume mixing rule was applied to calculate SCRI based on in-situ chemical composition data, that is, a five-component dust mixture, and literature data for various mineral components. For a better entirely spectral coverage we would like to stress the need for extended SCRI data, e.g., in the solar spectral range and for further minerals. Moreover, more complex mixing rules to derive an ensemble refractive index might be interesting to discuss.

Higher vertical resolution in aircraft-based aerosol particle measurements of size distribution and total number concentration in conjunction with chemical analyses is the basis for a more realistic treatment of aerosols in radiative transfer simulations, since this provides more detailed information about the vertical layering and structure of an aerosol-loaden atmosphere. In particular, this might be important to consider in aircraft-based observations of Saharan mineral dust during its long-range transport from North Africa to America.

Our radiative forcing and heating effect simulations refer to a local atmospheric situation only. It has been shown that particle non-sphericity has a non-negligible radiative impact, e.g., on the heating effect within the dust layer. However, the climate impact of particle non-sphericity and its dynamical feedback on regional or global scale can only be explored applying more complex dynamical models in which the dust optical properties are parameterised. Our databases of single 
scattering properties, mainly established w.r.t. mineral dust, together with the precious SAMUM-1 data may be applied to derive parameterisations of the optical properties of mineral dust to account for it in regional and global models.

Radiative transfer quantities as the ensemble optical properties may not be bijective functions of certain free parameters, e.g., the micro-physical properties of the aerosol particles as typical particle size and imaginary part of its complex refractive index. This fact may be problematic vice versa when deriving, e.g., micro-physical aerosol properties from standard radiometric or lidar measurements (inversion) in aerosol retrievals. With regard to the latter, the implication of our work is that they have to consider the terms "particle shape" and "size equivalence" of the naturally non-spherical particles. Additionally, the application of polarisation-based aerosol retrievals to polarimetric data seems promising to minimise uncertainties.

Acknowledgements. This study is based on precious in-situ data sampled during the bundle project SAMUM, which was funded by the German Research Foundation (DFG).

Edited by: Q. Fu

\section{References}

Anderson, G. P., Clough, S. A., Kneiyzs, F. X., Chetwynd, J. H., and Shettle, E. P.: AFGL Atmospheric Constituent Profiles (0120 km), AFGL-TR-86-0110, AFGL (OPI), Hanscom AFB, MA 01736, 1986.

Ansmann, A., Tesche, M., Knippertz, P., Bierwirth, E., Althausen, D., Müller, D., and Schulz, O.: Vertical profiling of convective dust plumes in southern Morocco during SAMUM, Tellus B, 61(1), 340-353, doi:10.1111/j.1600-0889.2008.00384.x, 2009.

Baldridge, A. M., Hook, S. J., Grove, C. I., and Rivera, G.: The ASTER spectral library version 2.0, Remote Sens. Environ., 113, 711-715, doi:10.1016/j.rse.2008.11.007, 2009.

Bates, D. R.: Rayleigh scattering by air, Planet. Space Sci., 32, 785-790, 1984.

Bierwirth, E., Wendisch, M., Ehrlich, A., Heese, B., Tesche, M., Althausen, D., Schladitz, A., Müller, D., Otto, S., Trautmann, T., Dinter, T., von Hoyningen-Huene, W., and Kahn, R.: Spectral surface albedo over Morocco and its impact on radiative forcing of Saharan dust, Tellus B, 61(1), 252-269, doi:10.1111/j.16000889.2008.00395.x, 2009.

Bodhaine, B. A., Wood, N. B., Dutton, E. G., and Slusser, J. R.: On Rayleigh optical depth calculations, J. Atmos. Ocean. Techn., 16, 1854-1861, 1999.

Bowker, D. E., Davis, R. E., Myrik, D. L., Stacy, K., and Jones, W. T.: Spectral reflectance of natural targets for use in remote sensing studies, NASA Ref. Publ., 1139, 1985.

Bucholtz, A.: Rayleigh-scattering calculations for the terrestrial atmosphere, Appl. Opt., 34(15), 2765-2773, 1995.

Cattrall, C., Carder, K. L., and Gordon, H. R.: Columnar aerosol single-scattering albedo and phase function retrieved from sky radiance over the ocean: Measurements of Saharan dust, J. Geophys. Res., 108(D9), 4287, doi:10.1029/2002JD002497, 2003.
Chen, G., Ziemba, L. D., Chu, D. A., Thornhill, K. L., Schuster, G. L., Winstead, E. L., Diskin, G. S., Ferrare, R. A., Burton, S. P., Ismail, S., Kooi, S. A., Omar, A. H., Slusher, D. L., Kleb, M. M., Reid, J. S., Twohy, C. H., Zhang, H., and Anderson, B. E.: Observations of Saharan dust microphysical and optical properties from the Eastern Atlantic during NAMMA airborne field campaign, Atmos. Chem. Phys., 11, 723-740, doi:10.5194/acp11-723-2011, 2011.

Cornette, W. M., Acharya, P. K., Robertson, D. C., and Anderson, G. P.: Moderate spectral atmospheric radiance and transmittance code (MOSART), Rep. R-057-94 (11-30), Photon Res. Assoc., Inc., La Jolla, Calif., 1994.

Coz, E., Gómez-Moreno, F. J., Pujadas, M., Casuccio, G. S., Lersch, T. L., and Artíñano, B.: Individual particle characteristics of North African dust under different longrange transport scenarios, Atmos. Environ., 43, 1850-1863, doi:10.1016/j.atmosenv.2008.12.045, 2009.

Dall'Osto, M., Harrison, R. M., Highwood, E. J., O'Dowd, C., Ceburnis, D., Querol, X., and Achterberg, E. P.: Variation of the mixing state of Saharan dust particles with atmospheric transport, Atmos. Environ., 44, 3135-3146, doi:10.1016/j.atmosenv.2010.05.030, 2010.

Dobbie, J. S., Li, J., and Chýlek, P.: Two- and four-stream optical properties for water clouds and solar wavelengths, J. Geophys. Res., 104(D2), 2067-2079, 1999.

Doherty, O. M., Riemer, N., and Hameed, S.: Saharan mineral dust transport into the Caribbean: Observed atmospheric controls and trends, J. Geophys. Res., 113, D07211, doi:10.1029/2007JD009171, 2008.

Dubovik, O., Holben, B. N., Eck, T. F., Smirnov, A., Kaufman, Y. J., King, M. D., Tanré, D., and Slutsker, I.: Variability of absorption and optical properties of key aerosol types observed in worldwide locations, J. Atmos. Sci., 59, 590-608, 2002.

Esselborn, M., Wirth, M., Fix, A., Weinzierl, B., Rasp, K., Tesche, M., and Petzold, A.: Spatial distribution and optical properties of Saharan dust observed by airborne high spectral resolution lidar during SAMUM 2006, Tellus B, 61(1), 131-143, doi:10.1111/j.1600-0889.2008.00394.x, 2009.

Feister, U. and Grewe, R.: Spectral albedo measurements in the UV and visible region over different types of surfaces, Photochem. Photobiol., 62(4), 736-744, 1995.

Fu, Q., Thorsen, T. J., Su, J., Ge, J. M., and Huang, J. P.: Test of Mie-based single-scattering properties of non-spherical dust aerosols in radiative flux calculations, J. Quant. Spectrosc. Ra., 110, 1640-1653, 2009.

Gómez-Amo, J. L., di Sarra, A., Meloni, D., Cacciani, M., and Utrillas, M. P.: Sensitivity of shortwave radiative fluxes to the vertical distribution of aerosol single scattering albedo in the presence of a desert dust layer, Atmos. Environ., 44, 2787-2791, doi:10.1016/j.atmosenv.2010.04.041, 2010.

Hand, V. L., Capes, G., Vaughan, D. J., Formenti, P., Haywood, J. M., and Coe, H.: Evidence of internal mixing of African dust and biomass burning particles by individual particle analysis using electron beam techniques, J. Geophys. Res., 115, D13301, doi:10.1029/2009JD012938, 2010.

Hansell, R. A., Tsay, S. C., Ji, Q., Hsu, N. C., Jeong, M. J., Wang, S. H., Reid, J. S., Liou, K. N., and Ou, S. C.: An assessment of the surface longwave direct radiative effect of airborne saharan dust during the NAMMA field campaign, J. Atmos. Sci., 67, 10481065, doi:10.1175/2009JAS3257.1, 2010. 
Haywood, J., Francis, P., Osborne, S., Glew, M., Loeb, N., Highwood, E., Tanré, D., Myhre, G., Formenti, P., and Hirst, E.: Radiative properties and direct radiative effect of Saharan dust measured by the C-130 aircraft during SHADE: 1 . Solar spectrum, J. Geophys. Res., 108(D18), 8577, doi:10.1029/2002JD002687, 2003.

Heintzenberg, J.: The SAMUM-1 experiment over Southern Morocco: Overview and introduction, Tellus B, 61(1), 2-11, doi:10.1111/j.1600-0889.2008.00403.x, 2009.

$\mathrm{Hu}$, Y. X. and Stamnes, K.: An accurate parameterization of the radiative properties of water clouds suitable for use in climate models, J. Clim., 6, 728-742, 1993.

Johnson, B. T., Osborne, S. R., Haywood, J. M., and Harrison, M. A. J.: Aircraft measurements of biomass burning aerosol over West Africa during DABEX, J. Geophys. Res., 113, D00C06, doi:10.1029/2007JD009451, 2008a.

Johnson, B. T., Heese, B., McFarlane, S. A., Chazette, P., Jones, A., and Bellouin, N.: Vertical distribution and radiative effects of mineral dust and biomass burning aerosol over West Africa during DABEX, J. Geophys. Res., 113, D00C12, doi:10.1029/2008JD009848, 2008b.

Johnson, B. T., Christopher, S., Haywood, J. M., Osborne, S. R., McFarlane, S., Hsu, C., Salustro, C., and Kahn, R.: Measurements of aerosol properties from aircraft, satellite and groundbased remote sensing: A case-study from the Dust and Biomassburning Experiment (DABEX), Q. J. Roy. Meteorolog. Soc., 135, 922-934, 2009.

Kahnert, M.: Reproducing the optical properties of ne desert dust aerosols using ensembles of simple model particles, J. Quant. Spectrosc. Ra., 85, 231-249, 2004.

Kahnert, M. and Kylling, A.: Radiance and flux simulations for mineral dust aerosols: Assessing the error due to using spherical or spheroidal model particles, J. Geophys. Res., 109, D09203, doi:10.1029/2003JD004318, 2004.

Kahnert, M., Nousiainen, T., and Veihelmann, B.: Spherical and spheroidal model particles as an error source in aerosol climate forcing and radiance computations: A case study for feldspar aerosols, J. Geophys. Res., 110, D18S13, doi:10.1029/2004JD005558, 2005.

Kahnert, M. and Nousiainen, T.: Uncertainties in measured and modelled asymmetry parameters of mineral dust aerosols, J. Quant. Spectrosc. Ra., 100, 173-178, 2006.

Kahnert, M., Nousiainen, T., and Räisänen, P.: Mie simulations as an error source in mineral aerosol radiative forcing calculations, Q. J. Roy. Meteor. Soc., 133, 299-307, 2007.

Kandler, K., Schütz, L., Deutscher, C., Ebert, M., Hofmann, H., Jäckel, S., Jaenicke, R., Knippertz, P., Lieke, K., Massling, A., Petzold, A., Schladitz, A., Weinzierl, B., Wiedensohler, A., Zorn, S., and Weinbruch, S.: Size distribution, mass concentration, chemical and mineralogical composition and derived optical parameters of the boundary layer aerosol at Tinfou, Morocco, during SAMUM 2006, Tellus B, 61(1), 32-50, doi:10.1111/j.16000889.2008.00385.x, 2009.

Kaufman, Y. J., Tanré, D., Dubovik, O., Karnieli, A., Blaustein, J., and Remer, L. A.: Absorption of sunlight by dust as inferred from satellite and ground-based remote sensing, Geophys. Res. Lett., 28(8), 1479-1482, 2001.

Li, Z., Goloub, P., Blarel, L., Damiri, B., Podvin, T., and Jankowiak, I.: Dust optical properties retrieved from ground-based polarimetric measurements, Appl. Opt., 46(9), 1548-1553, 2007.
Lindner, T. H. and Li, J.: Parameterization of the optical properties for water clouds in the infrared, J. Clim., 13, 1797-1805, 2000.

Linke, C., Möhler, O., Veres, A., Mohácsi, Á., Bozóki, Z., Szabó, G., and Schnaiter, M.: Optical properties and mineralogical composition of different Saharan mineral dust samples: a laboratory study, Atmos. Chem. Phys., 6, 3315-3323, doi:10.5194/acp-63315-2006, 2006.

Mallet, M., Tulet, P., Serça, D., Solmon, F., Dubovik, O., Pelon, J., Pont, V., and Thouron, O.: Impact of dust aerosols on the radiative budget, surface heat fluxes, heating rate profiles and convective activity over West Africa during March 2006, Atmos. Chem. Phys., 9, 7143-7160, doi:10.5194/acp-9-7143-2009, 2009.

McConnell, C. L., Highwood, E. J., Coe, H., Formenti, P., Anderson, B., Osborne, S., Nava, S., Desboeufs, K., Chen, G., and Harrison, M. A. J.: Seasonal variations of the physical and optical characteristics of Saharan dust: Results from the Dust Outflow and Deposition to the Ocean (DODO) experiment, J. Geophys. Res., 113, D14S05, doi:10.1029/2007JD009606, 2008.

McConnell, C. L., Formenti, P., Highwood, E. J., and Harrison, M. A. J.: Using aircraft measurements to determine the refractive index of Saharan dust during the DODO Experiments, Atmos. Chem. Phys., 10, 3081-3098, doi:10.5194/acp-10-3081-2010, 2010.

McFarlane, S. A., Kassianov, E. I., Barnard, J., Flynn, C., and Ackerman, T. P.: Surface shortwave aerosol radiative forcing during the Atmospheric Radiation Measurement Mobile Facility deployment in Niamey, Niger, J. Geophys. Res., 114, D00E06, doi:10.1029/2008JD010491, 2009.

Müller, D., Weinzierl, B., Petzold, A., Kandler, K., Ansmann, A., Müller, T., Tesche, M., Freudenthaler, V., Esselborn, M., Heese, B., Althausen, D., Schladitz, A., Otto, S., and Knippertz, P.: Mineral dust observed with AERONET Sun photometer, Raman lidar, and in situ instruments during SAMUM 2006: Shapeindependent particle properties, J. Geophys. Res., 115, D07202, doi:10.1029/2009JD012520, 2010.

Nicolet, M.: On the molecular scattering in the terrestrial atmosphere: An empirical formula for its calculation in the homosphere, Planet. Space Sci., 32(11), 1467-1468, 1984.

Ogunjobi, K. O., He, Z., and Simmer, C.: Spectral aerosol optical properties from AERONET Sun-photometric measurements over West Africa, Atmos. Res., 88, 89-107, 2008.

Osborne, S. R., Johnson, B. T., Haywood, J. M., Baran, A. J., Harrison, M. A. J., and McConnell, C. L.: Physical and optical properties of mineral dust aerosol during the Dust and Biomass-burning Experiment, J. Geophys. Res., 113, D00C03, doi:10.1029/2007JD009551, 2008.

Otto, S., de Reus, M., Trautmann, T., Thomas, A., Wendisch, M., and Borrmann, S.: Atmospheric radiative effects of an in situ measured Saharan dust plume and the role of large particles, Atmos. Chem. Phys., 7, 4887-4903, doi:10.5194/acp-7-4887-2007, 2007.

Otto, S., Bierwirth, E., Weinzierl, B., Kandler, K., Esselborn, M., Tesche, M., Schladitz, A., Wendisch, M., and Trautmann, T.: Solar radiative effects of a Saharan dust plume observed during SAMUM assuming spheroidal model particles, Tellus B, 61(1), 270-296, doi:10.1111/j.1600-0889.2008.00389.x, 2009.

Otto, S.: Optische Eigenschaften nichtkugelförmiger Saharamineralstaub partikel und deren Einfluss auf den Strahlungstransport in der Erdatmosphäre, $\mathrm{PhD}$ thesis, to be submitted for University of Leipzig, 2011. 
Parkin, D. W., Phillips, D. R., Sullivan, R. A. L., and Johnson, L. R.: Airborne dust collections down the Atlantic, Q. J. Roy. Meteorol. Soc., 98, 798-808, 1972.

Prospero, J. M., Landing, W. M., and Schulz, M.: African dust deposition to Florida: Temporal and spatial variability and comparisons to models, J. Geophys. Res., 115, D13304, doi:10.1029/2009JD012773, 2010.

Quijano, A. L., Sokolik, I. N., and Toon, O. B.: Influence of the aerosol vertical distribution on the retrievals of aerosol optical depth from satellite radiance measurements, Geophys. Res. Lett., 27(21), 3457-3460, 2000.

Raut, J.-C. and Chazette, P.: Radiative budget in the presence of multi-layered aerosol structures in the framework of AMMA SOP-0, Atmos. Chem. Phys., 8, 6839-6864, doi:10.5194/acp-86839-2008, 2008.

Reid, J. S., Jonsson, H. H., Maring, H. B., Smirnov, A., Savoie, D. L., Cliff, S. S., Reid, E. A., Livingston, J. M., Meier, M. M., Dubovik, O., and Tsay, S.-C.: Comparison of size and morphological measurements of coarse mode dust particles from Africa, J. Geophys. Res., 108(D19), 8593, doi:10.1029/2002JD002485, 2003.

Rothman, L. S., Gordon, I. E., Barbe, A., Chris Benner, D., Bernath, P. F., Birk, M., Boudon, V., Brown, L. R., Campargue, A., Champion, J.-P., Chance, K., Coudert, L. H., Dana, V., Devi, V. M., Fally, S., Flaud, J.-M., Gamache, R. R., Goldman, A., Jacquemart, D., Kleiner, I., Lacome, N., Lafferty, W. J., Mandin, J.-Y., Massie, S. T., Mikhailenko, S. N., Miller, C. E., Moazzen-Ahmadi, N., Naumenko, O. V., Nikitin, A. V., Orphal, J., Perevalov, V. I., Perrin, A., Predoi-Cross, A., Rinsland, C. P., Rotger, M., Simeckova, M., Smith, M. A. H., Sung, K., Tashkun, S. A., Tennyson, J., Toth, R. A., Vandaele, A. C., and Vander Auwera, J.: The HITRAN 2008 molecular spectroscopic database, J. Quant. Spectrosc. Ra., 110, 533-572, 2009.

Schmid, B., Livingston, J. M., Russell, P. B., Durkee, P. A., Jonsson, H. H., Collins, D. R., Flagan, R. C., Seinfeld, J. H., Gassó, S., Hegg, D. A., Öström, E., Noone, K. J., Welton, E. J., Voss, K. J., Gordon, H. R., Formenti, P., and Andreae, M. O.: Clear-sky closure studies of lower tropospheric aerosol and water vapor during ACE-2 using airborne sunphotometer, airborne in-situ, spaceborne, and ground-based measurements, Tellus B, 52, 568-593, 2000.

Schmidt, K., Wauer, J., Rother T., and Trautmann, T.: Scattering database for spheroidal particles, Appl. Opt., 48(11), 2154-2164, 2009.

Schröder, T.: Fernerkundung von Wasserinhaltsstoffen in Küstengewässern mit MERIS unter Anwendung expliziter und impliziter Atmosphärenkorrekturverfahren, $\mathrm{PhD}$, Freie Universität Berlin, 113 pp., 2004.

Schulz, F. M., Stamnes, K., and Stamnes, J. J.: Modeling the radiative transfer properties of media containing particles of moderately and highly elongated shape, Geophys. Res. Lett., 25, 44814484, 1998.
Schulz, F. M., Stamnes, K., and Stamnes, J. J.: Shape-dependence of the optical properties in size-shape distributions of randomly oriented prolate spheroids, including highly elongated shapes, J. Geophys. Res., 104, 9413-9421, 1999.

Shanmugam, P. and Ahn, Y. H.: Reference solar irradiance spectra and consequences of their disparities in remote sensing of the ocean colour, Ann. Geophys., 25, 1235-1252, doi:10.5194/angeo-25-1235-2007, 2007.

Shettle, E. P. and Fenn, R. W.: Models of the aerosols of the lower atmosphere and the effects of humidity variations on their optical properties, Project 7670, Air Force Geoph. Lab., Massachusetts, 1979.

Slingo, A.: A GCM parameterization for the shortwave radiative properties of water clouds, J. Atmos. Sci., 46(10), 1419-1427, 1989.

Sokolik, I. N., Winker, D. M., Bergametti, G., Gillette, D. A., Carmichael, G., Kaufman, Y. J., Gomes, L., Schütz, L., and Penner, J. E.: Introduction to special section: Outstanding problems in quantifying the radiative impacts of mineral dust, J. Geophys. Res., 106(D16), 18015-18028, doi:10.1029/2000JD900498, 2001.

Solmon, F., Mallet, M., Elguindi, N., Giorgi, F., Zakey, A., and Konaré, A.: Dust aerosol impact on regional precipitation over western Africa, mechanisms and sensitivity to absorption properties, Geophys. Res. Lett., 35, L24705, doi:10.1029/2008GL035900, 2008.

Stephens, G. L.: Optical properties of eight water cloud types, CSIRO Aust. Div. Atmos. Phys. Techn. Paper, No. 36, 1-35, 1979.

Tesche, M., Ansmann, A., Müller, D., Althausen, D., Mattis, I., Heese, B., Freudenthaler, V., Wiegner, M., Esselborn, M., Pisani, G., and Knippertz, P.: Vertical profiling of Saharan dust with Raman lidars and airborne HSRL in southern Morocco during SAMUM, Tellus B, 61(1), 144-164, doi:10.1111/j.16000889.2008.00390.x, 2009.

Thomas, G. E. and Stamnes, K.: Radiative transfer in the atmosphere and ocean, Cambridge University Press, 546 pp., 1999.

Veihelmann, B., Nousiainen, T., Kahnert, M., and van der Zande, W. J.: Light scattering by small feldspar particles simulated using the Gaussian random sphere geometry, J. Quant. Spectrosc. Ra., 100, 393-405, 2006.

Weinzierl, B., Petzold, A., Esselborn, M., Wirth, M., Rasp, K., Kandler, K., Schütz, L., Koepke, P., and Fiebig, M.: Airborne measurements of dust layer properties, particle size distribution and mixing state of Saharan dust during SAMUM 2006, Tellus B, 61(1), 96-117, doi:10.1111/j.1600-0889.2008.00392.x, 2009.

Zdunkowski, W., Trautmann, T., and Bott, A.: Radiation in the atmosphere: A course in theoretical meteorology, Cambridge University Press, 496 pp., 2007. 